\title{
The AMPK-related kinase NUAK1 controls cortical axons branching though a local modulation of mitochondrial metabolic functions
}

\author{
Marine Lanfranchi, Géraldine Meyer-Dilhet, Raphael Dos Reis, Audrey Garcia, Camille \\ Blondet, Luc Javin, Alizée Amar and Julien Courchet ${ }^{\#}$
}

\begin{abstract}
Affiliation : University of Lyon, Université Claude Bernard Lyon 1, CNRS UMR-5310, INSERM U-1217, Institut NeuroMyoGène, F-69622, Villeurbanne, France

\# Correspondence: Julien Courchet, DVM, Ph.D., julien.courchet@univ-lyon1.fr
\end{abstract}

\begin{abstract}
The precise regulation of the cellular mechanisms underlying axonal morphogenesis is essential to the formation of functional neuronal networks. We previously identified the autism-candidate kinase NUAK1 as a central regulator of axon branching in mouse cortical neurons through the control of mitochondria trafficking. How does local mitochondrial position or function regulate axon branching during development? Here, we characterized the metabolic regulation in the developing axon and report a marked metabolic decorrelation between axon elongation and collateral branching. We next solved the cascade of event leading to presynaptic clustering and mitochondria recruitment during spontaneous branch formation. Interestingly and contrary to peripheral neurons, mitochondria are recruited after but not prior to branch formation in cortical neurons. Using flux metabolomics and fluorescent biosensors, we observed that NUAK1 deficiency significantly impairs mitochondrial metabolism and axonal ATP concentration. Upregulation of mitochondrial function is sufficient to rescue axonal branching in NUAK1 null neurons in vitro and in vivo. Altogether, our results indicate that NUAK1 exerts a dual function during axon branching through its ability to control mitochondria distribution and activity, and suggest that a mitochondrial-dependent remodeling of local metabolic homeostasis plays a critical role during axon morphogenesis.
\end{abstract}

\section{INTRODUCTION}

In mammals, cortical circuits are organized into complex networks of neurons interconnected through long-range axonal projections. The establishment of circuit connectivity occurs during a protracted period of embryonic and postnatal development through a series of tightly regulated cellular processes whose disruption can lead to socially-devastating neurodevelopmental disorders such as autism spectrum disorders (ASD), schizophrenia, epilepsy or mental retardation (del Pino et al., 2018; Piven et al., 2017). Axon morphogenesis is a multistep process culminating with the formation of axonal branches to form a network that is later refined through a process of selection of functional contacts and elimination by pruning (Kalil and Dent, 2014; Lewis et al., 2013). The formation and refinement of terminal axonal branches relies on a balance between synaptic activity and target-derived extracellular neurotrophins (Mizuno et al., 2007; C.-L. Wang et al., 2007). These signals converge on the activation of intracellular signaling pathways mediating a cascade of cellular events such as cytoskeleton remodeling, addition of membrane or local protein translation (Brosig et al., 2019; Dent et al., 1999; Dent and Kalil, 2001; Hu et al., 2012; Ponomareva et al., 2014; A. Schwarz et al., 1995; Spillane et al., 2012; 2013; Wong et al., 2017) that are highly taxing energetically and are thought to induce a local increase in the metabolic turnover. Yet the spatial diffusion of metabolic molecules such as ATP is limited, implying that cellular energy production must match the local demand. Understanding how these local mechanisms are set up and how they contribute to aspects of neuronal development such as the shaping of axonal complexity is therefore a key question in cellular neuroscience.

The local metabolic activity has been best studied at synapses (Lee et al., 2018; Rangaraju et al., 2019; Rossi and Pekkurnaz, 2019), which account for the majority of ATP consumption in neurons to ensure ionic homeostasis and synaptic vesicle recycling (Attwell and Laughlin, 2001; Harris et al., 2012; Rangaraju et al., 2014; Vos et al., 2010). In 
agreement with this local metabolic need, mitochondria are actively transported to and captured at presynapses (J. Courchet et al., 2013; Devine and Kittler, 2018; Hollenbeck and Saxton, 2005; Misgeld and T. L. Schwarz, 2017). Mitochondrial function has been proposed to support synaptic release through a crosstalk between ATP-producing oxidative phosphorylations (Ashrafi et al., 2020; Rangaraju et al., 2014) and calcium buffering (Hirabayashi et al., 2017; Kwon et al., 2016; Vaccaro et al., 2017; Villegas et al., 2014), converging on the fine-tuned regulation of synaptic vesicle release. In contrast, the regulation of local metabolism in immature neurons and during axon morphogenesis is far less wellunderstood. Recent studies uncovered that mitochondria function is critical for neuronal development and cortical circuits formation (Fernandez et al., 2019; Klein Gunnewiek et al., 2020; Oruganty-Das et al., 2012).

Deregulation of mitochondria positioning, morphology or function disrupts the formation of axonal projections in vivo (J. Courchet et al., 2013; Fernandez et al., 2019; Lewis et al., 2018). In developing retinal and sensory axons, mitochondria function has been linked to the local protein synthesis required for cytoskeleton remodeling and the conversion of filopodia into a collateral axonal branch (Cioni et al., 2019; Spillane et al., 2013; Wong et al., 2017). However it is unclear if all neuronal subtypes or if all modalities of axonal branching rely on the same mechanisms for branch formation, growth or consolidation. Hence there is a need to better understand the cellular mechanisms underlying the role of mitochondrial function in the formation and refinement of axon morphogenesis and thereby the establishment of circuit connectivity.

We previously identified that a signaling pathway formed by the kinases LKB1 (STK11) and NUAK1 (ARK5) control cortical axon branching through the regulation of mitochondria capture at immature presynaptic sites (J. Courchet et al., 2013). NUAK1 belongs to a family of 14 closely related kinases related to the metabolic regulator AMPK (PRKAA) defining the so-called AMPK-related kinases (AMPKRK) family (Lizcano et al., 2004). NUAK1 expression is strongly enriched in the developing mouse cortex (Hirano et al., 2006; Ohmura et al., 2012). Rare de novo mutations of NUAK1 have been associated to several neurodevelopmental disorders including Autism Spectrum Disorders (ASD) (lossifov et al., 2014; 2012), Attention Deficit / Hyperactivity Disorders (ADHD) (Alemany et al., 2015), cognitive impairment (Johnson et al., 2016) or hydrocephaly (Vojinovic et al., 2018). In mice, NUAK1 heterozygosity affects cortical development, leading to an array of anatomical and behavioral deficits ( $\mathrm{V}$. Courchet et al., 2018). So far, the cellular functions of NUAK1 remain incompletely known. It has been linked to the control of the actomyosin cytoskeleton through the phosphorylation of the Protein Phosphatase 1 (PP1) regulatory subunit MYPT1 (Zagórska et al., 2010). Furthermore NUAK1 directly phosphorylates the microtubule-associated protein TAU (Lasagna-Reeves et al., 2016) and accordingly NUAK1 inhibition can alleviate some of the cellular and behavioral effects in a mouse model of tauopathy. In parallel NUAK1 function has been tied to the regulation of mitochondrial metabolism in Mycoverexpressing cancer cells, who rely on NUAK1 expression to maintain metabolic homeostasis and for survival (Liu et al., 2012).

Our previous observation that axonal mitochondria capture at nascent presynaptic boutons is essential for terminal axon branching (J. Courchet et al., 2013) raised a central and unresolved question pertaining to the function of presynaptic mitochondria in axon branching. In this study, we explored the hypothesis that presynaptic mitochondria have a unique property with regard to their ability to promote branch formation or stabilization in cortical pyramidal neurons (PNs). We observed that axon elongation and collateral branching rely on distinct metabolic pathways. We further characterized that mitochondria accumulate specifically at presynaptic sites located at axonal branch points, and that unlike presynaptic boutons that are formed before axonal branches, mitochondria recruitment occurs after the onset of branch formation. Through mitochondria photoinactivation, we confirmed that in cortical PNs, mitochondria are required for branch stabilization rather than branch initiation. We subsequently characterized mitochondrial function in NUAK1 deficient neurons and report that NUAK1 controls not only mitochondrial trafficking, but also mitochondrial metabolic activity. Finally using pharmacological and genetic approaches to boost mitochondrial fitness, we observed that a metabolic upregulation is sufficient to rescue axonal branching in NUAK1 deficient neurons in vitro and in vivo. Overall, our results indicate that the kinase NUAK1 exerts a dual effect on mitochondria trafficking and activity in cortical PNs and suggest a two-hit model by which branch stabilization relies not only on the proper localization of mitochondria, but also on their local activity.

\section{RESULTS}

\section{Cortical axon elongation and collateral branching rely on distinct metabolic pathways}




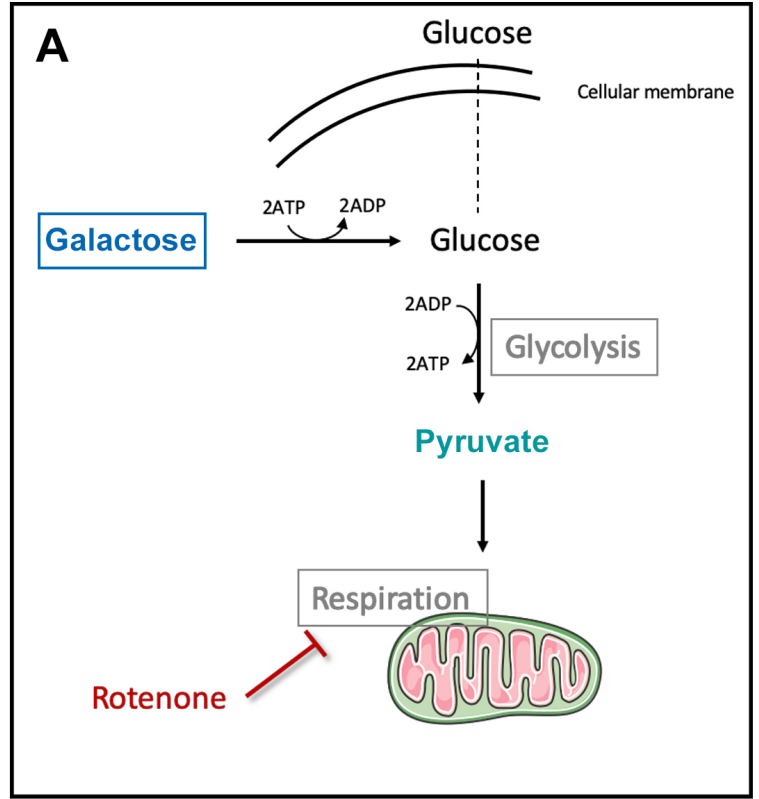

C

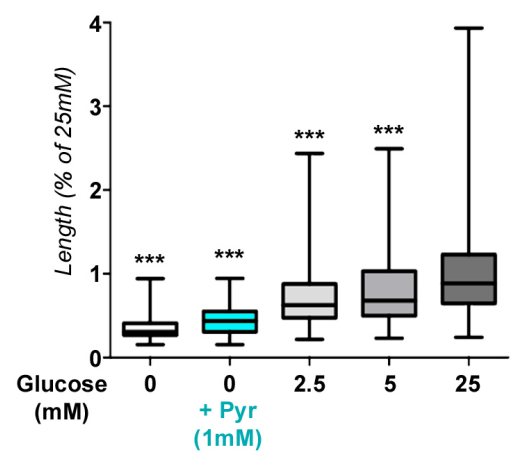

D

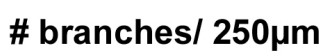

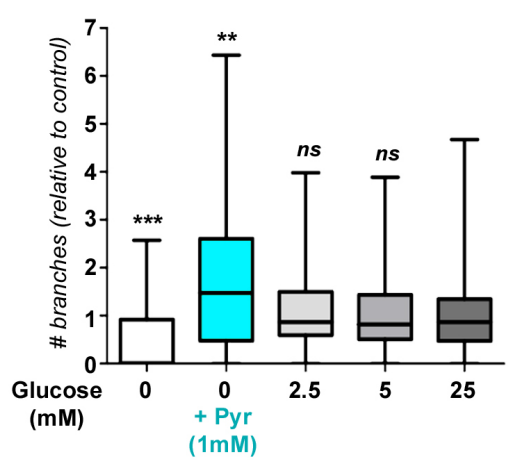

Axon length

E
B

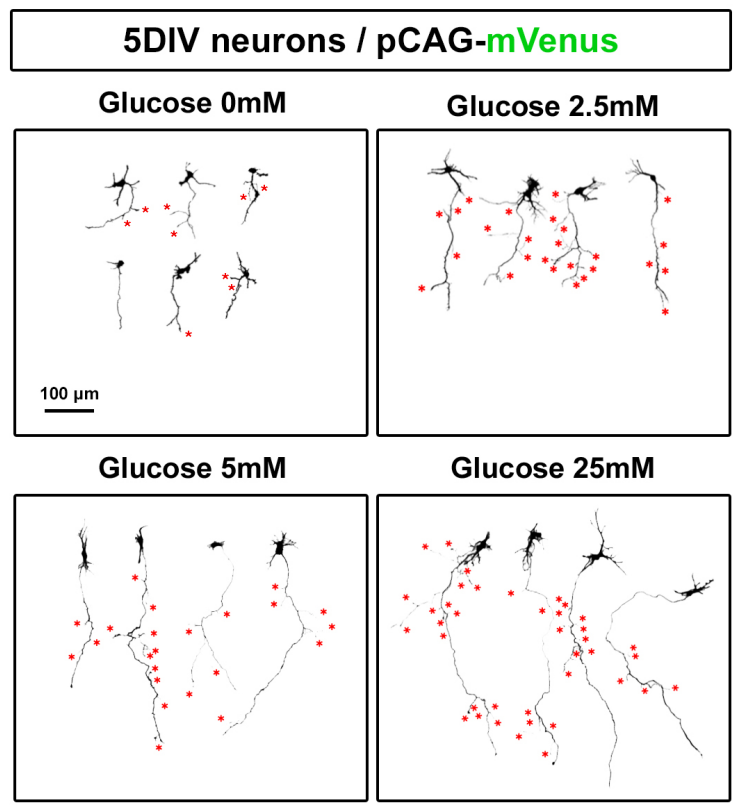

Axon length

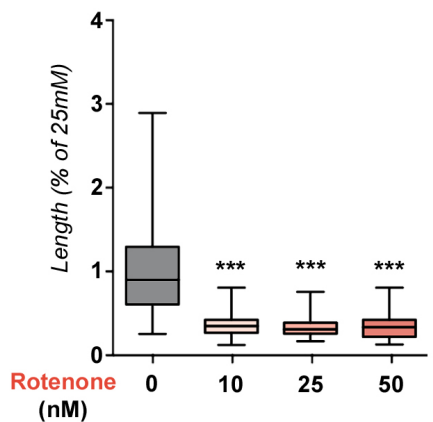

$\mathbf{F}$

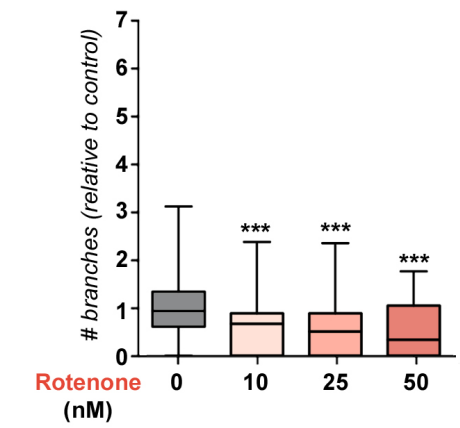

G Axon length

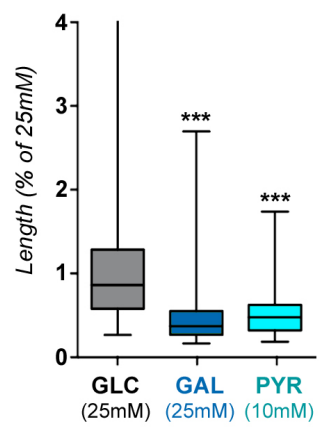

H

\# branches/ 250 $\mu \mathrm{m}$

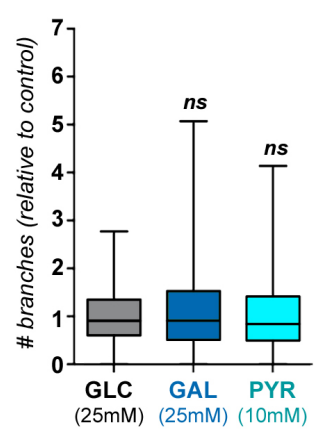

Figure 1: differential requirement of glycolysis and oxidative metabolism for axon growth and branching

(A) Main pathways of glucose metabolism. Galactose was used to negate the metabolic effect of glycolysis. Pyruvate was used to support mitochondrial metabolism in a glucose-free medium. Low doses of rotenone were used to lower mitochondrial Complex I activity.

(B) Representative images of mVenus expressing cortical neurons (5DIV) cultured in Neurobasal medium containing the indicated doses of glucose. Red stars point to collateral branches of the axon.

(C-H) Quantification of axon length and collateral branches of 5DIV neurons in the indicated conditions: (C-D) medium containing increasing concentrations of glucose. (E-F) $25 \mathrm{mM}$ glucose-containing medium with increasing doses of rotenone. (G-H) medium containing either glucose $(25 \mathrm{mM})$, or galactose $(24 \mathrm{mM})+$ glucose $(1 \mathrm{mM})$, or pyruvate $(10 \mathrm{mM})$ without glucose.

Box-plot: $75^{\text {th }}$ percentile, median and $25^{\text {th }}$ percentile. Statistical tests: Kruskal-Wallis test with Dunn's post-test (each condition compared to untreated $25 \mathrm{mM}$ condition). (C-D) $\mathrm{N}_{(0 \mathrm{mM})}=48, \mathrm{~N}_{(0 \mathrm{mM}+\mathrm{Pyr})}=75, \mathrm{~N}_{(2.5 \mathrm{mM})}=244, \mathrm{~N}_{(5 \mathrm{mM})}=191, \mathrm{~N}_{(25 \mathrm{mM})}=238$. (E-F) $\mathrm{N}_{(0 \mathrm{nM})}=120, \mathrm{~N}_{(10 \mathrm{nM})}=102, \mathrm{~N}_{(20 \mathrm{nM})}=82$, $\left.\mathrm{N}_{(50 n \mathrm{n})}\right)=44 .(\mathrm{G}-\mathrm{H}) \mathrm{N}_{(\text {Glucose })}=246, \mathrm{~N}_{\text {(Galactose })}=248, \mathrm{~N}_{\text {(Pyruvate })}=130$

We first tested how axon morphogenesis rely on glucose metabolism (Fig. 1A). Cortical and hippocampal neuronal cultures are classically grown in a glucose-rich medium. To determine to what extent axonal elongation and collateral branching rely on glucose as a source of carbon, we cultured cortical neurons in neurobasal medium with no glucose, or with low $(2.5 \mathrm{mM})$, medium $(5 \mathrm{mM})$ and high $(25 \mathrm{mM})$ 
concentrations of glucose. We observed a marked dose-response effect of medium glucose concentration on axon development (Fig. 1B). Quantifications revealed that axonal length increases as a function of glucose concentration (Fig. 1C). In contrast, the number of collateral branches was dependent upon the presence, but not quantity of glucose (Fig. 1D). Interestingly a low dose of pyruvate $(1 \mathrm{mM})$ was also sufficient to support axonal branching, suggesting that collateral branch formation or stabilization is largely dependent upon mitochondrial metabolism.

To test this hypothesis further, we next used strategies to decouple the two main pathways of glucose catabolism, i.e. glycolysis and mitochondrial respiration (Fig. 1A). We used low doses of rotenone, an inhibitor of OXPHOS complex I, to downregulate mitochondrial oxidative phosphorylation capacity without affecting glycolysis. This led to a decrease of both axon length and collateral branching (Fig. 1E-F and Fig. S1A). Conversely, we bypassed glycolysis either by replacing glucose by galactose (a 6-carbon sugar catabolized by the glycolytic machinery but negating the net ATP production of glycolysis), or by adding pyruvate to a no-glucose medium. In both case, axon branching was largely equivalent to control conditions (25mM glucose) despite a strong adverse effect on axon length (Fig. 1G-H and Fig. S1B-C). Interestingly glucose concentration also affected the number of dendritic branches formed by neurons. Dendrite growth and branching was reduced, albeit slightly, in conditions where glycolysis was bypassed, whereas reduction of dendritic growth and branching was significantly more pronounced upon mitochondria inhibition by rotenone (Fig. S1DF). Taken together, our results show distinct metabolic requirement for axon elongation and collateral branching and suggest that mitochondrial oxidative phosphorylation is necessary and sufficient for axon branch formation and/or consolidation.

\section{Mitochondria cluster at axonal branchpoint of cortical pyramidal neurons}

The importance of oxidative metabolism for axonal branching prompted us to define the position of axonal mitochondria relative to collateral branches in cortical pyramidal neurons (PNs). Indeed previous studies by us and others linked branching with the trafficking and distribution of axonal mitochondria (J. Courchet et al., 2013; Sainath et al., 2017; Spillane et al., 2013). We performed Ex Vivo Cortical Electroporations (EVCE) of plasmids encoding the fluorescent protein BFP together with mitochondriatargeted DsRed and the synaptic vesicle marker vGlut1-GFP as a marker of immature presynaptic boutons in cortical layer 2/3 PNs mitochondria. (Fig. 2A-B). After 5 days of culture in vitro (DIV), cortical PNs were fixed and imaged to analyze the distribution of mitochondria along the axon. Mitochondria were not distributed evenly along the axon, but rather we could observe zones of high mitochondrial density and zones of low mitochondrial density (Fig. 2A-C). The observed distance from a given mitochondrion to its nearest neighbor was significantly lower than the expected distance if mitochondria were evenly distributed along the axon (Fig. 2D), indicating that mitochondria form clusters along developing axons of cortical PNs. We observed that branchpoints are significantly closer to a mitochondrion than a random position in the axon (Fig. 2E) and that mitochondria density was higher at branch origin than in any random location along the axon shaft (Fig. 2F). Accordingly, branches were found in regions of high mitochondria density more frequently than in regions of low mitochondria density (Fig. 2G).

We previously identified that presynaptic capture of mitochondria is required for axonal branching in vitro and in vivo (J. Courchet et al., 2013). However, since vGlut1-positive puncta outnumber mitochondria along the axon, it is unclear if all presynaptic boutons are equally important for axonal branching. We thus performed extensive correlation of mitochondria position and presynaptic boutons along the axon (Fig. 2C). As it is the case for mitochondria, the distance between vGlut1-positive puncta was lower than expected if puncta were evenly distributed, indicating that presynaptic boutons form clusters along the axon (Fig. 2H). These clusters were significantly closer and denser at branchpoints compared to along the axon (Fig. 2l-J). Virtually all branches had a vGlut1positive cluster at their origin, and more than half of them also had resident mitochondria (Fig. 2K). Accordingly, presynaptic boutons located to branchpoint are more likely to be associated to mitochondria compared to boutons located along the axon (Fig. 2L). Finally, we tested if the distribution of synaptic puncta and mitochondria is conserved in an in vivo setting by performing In Utero Cortical Electroporation (IUCE) targeting callosal-projecting superficial (layer 2/3) PNs. The axon formed by these neurons projects toward the white matter (WM) and form collateral branches on layer 5 specifically (Fig. S2A-B). As expected, these axons form more synaptic puncta on layer 5 compared to the adjacent layers IV and VI. In comparison mitochondria density showed a progressive reduction with distance from the soma, but no specific enrichment in the branchrich layer 5 (Fig. S2C-D). However, as we observed in vitro, the large majority of axonal branches had a vGlut1-positive cluster at their origin, and branch- 
bioRxiv preprint doi: https://doi.org/10.1101/2020.05.18.102582; this version posted May 20, 2020. The copyright holder for this preprint (which was not certified by peer review) is the author/funder, who has granted bioRxiv a license to display the preprint in perpetuity. It is made available under aCC-BY-NC-ND 4.0 International license.

associated vGlut1 puncta were more likely to harbor a mitochondrion than vGlut1 puncta along the axon (Fig. S2E-F). Taken together, our results strongly suggest that mitochondria are not randomly recruited to nascent presynaptic boutons but rather preferentially associate to vGlut1 puncta located at branch origin.

\section{Mitochondria are recruited after, and not prior to branch formation}

Since our results presented so far relied primarily on static imaging, we next sought to determine the spatio-temporal dynamics of presynaptic bouton and mitochondria recruitment relative to branch formation. To do so we used EVCE and performed time-lapse
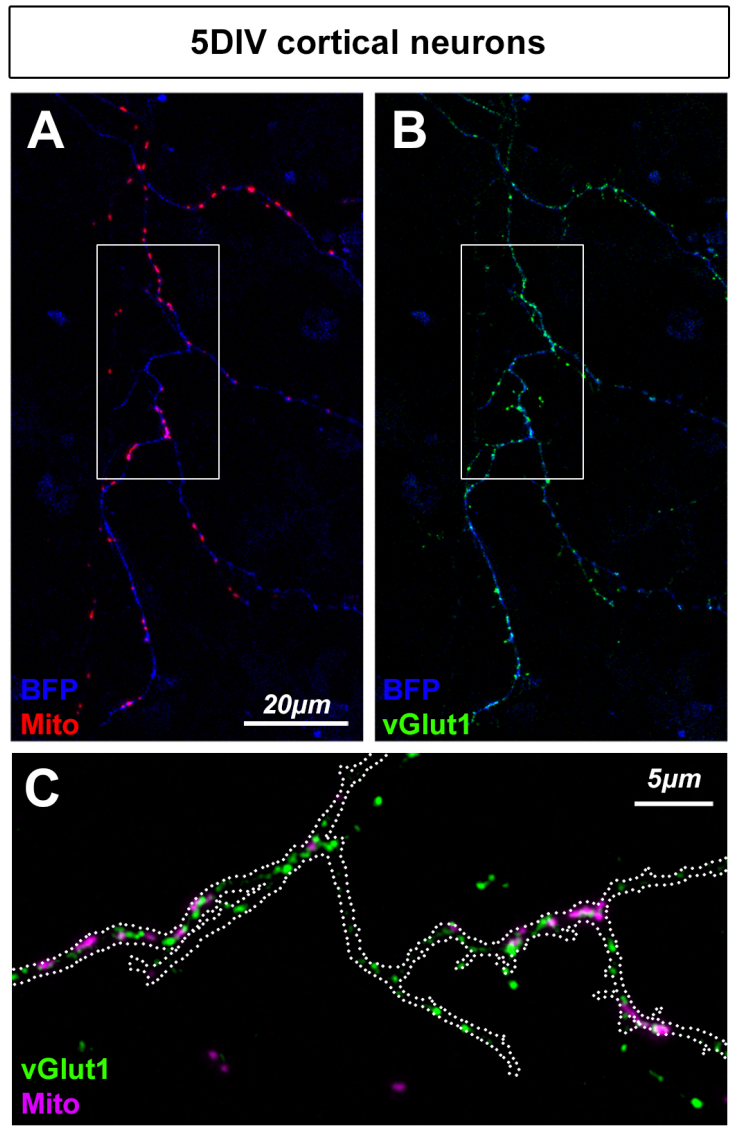

G

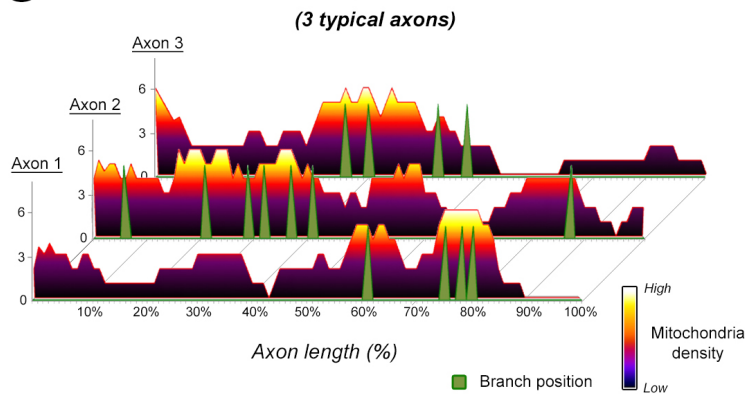

D Distance E between mitochondria

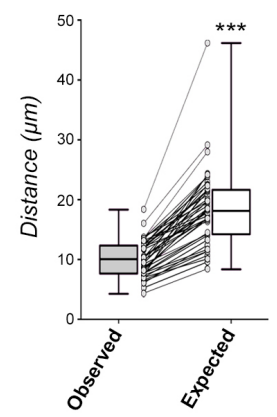
H Distance between vGlut1 puncta

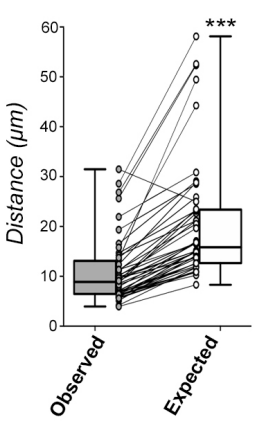

E Nearest
mitochondria

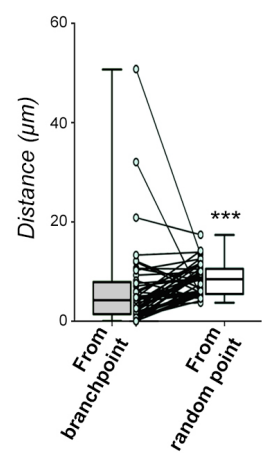

INearest vGlut1 puncta

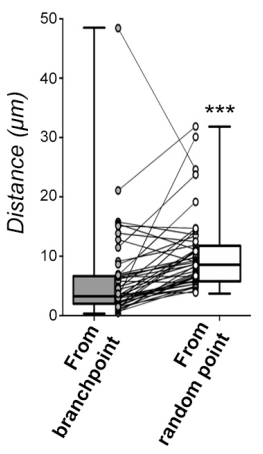

$\mathbf{F}$ Mitochondria
density

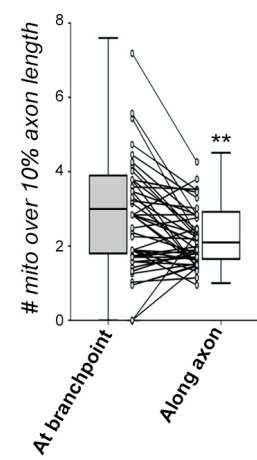

J vGlut1 puncta

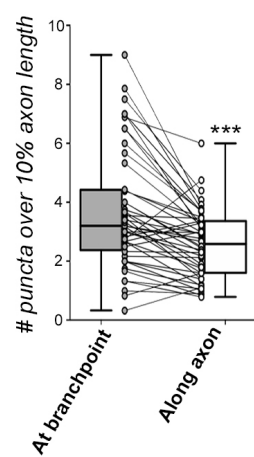

L vGlut1 / mitochondria association
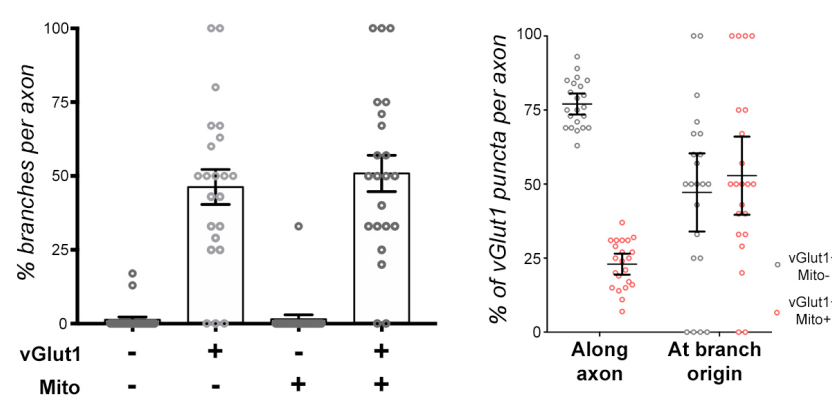

Figure 2: presynaptic sites and mitochondria clustering at axonal branchpoints

(A-B) Representative images of a 5DIV cortical neuron following expression of the mitochondrial marker mito-DsRed (A) or the presynaptic marker vGlut1-GFP (B). BFP was used to visualize neuronal morphology. Magnification of a segment of axon (C) shows vGlut1-GFP and mito-DsRed localization respective to branch origin (white dotted line).

(D-I) Quantification of mitochondria (D-F) and presynaptic puncta (G-I) distribution in the axon. The following quantifications were performed: $(D ; G)$ observed minimal distance between objects compared to expected distance if objects were evenly distributed. $(E ; H)$ Observed minimal distance from branchpoint compared to average distance from a random point along the axon. (F;I) Object density at branchpoint compared to average density along the axon. Box-plot: $75^{\text {th }}$ percentile, median and $25^{\text {th }}$ percentile. Individual dots represent average (per axon). Statistical tests: Wilcoxon matched-pairs ranked test. $\mathrm{N}_{\text {(mito })}=46, \mathrm{~N}_{(\mathrm{vGlut} 1)}=48$ out of 3 independent neuronal cultures.

(J) Representation of mitochondria density along the axon (normalized to axonal length from origin $(0 \%)$ to extremity $(100 \%)$. Position of collateral branches (green arrowhead) correlates with regions of high mitochondrial density.

(K) Quantification of branchpoint occupancy by either vGlut1+ puncta, mitochondria, or vGlut1+ puncta and mitochondria. Each point represents the value (\%) for a given axon. Bars: average \pm SEM. $N=22$ axons out of 2 independent experiments.

(L) Proportion of vGlut1 puncta devoid (grey) or associated to (red) mitochondria along the axon, and at branchpoints. $\mathrm{N}=22$ axons out of 2 independent experiments. Bars: median $\pm 95 \% \mathrm{Cl}$ 
bioRxiv preprint doi: https://doi.org/10.1101/2020.05.18.102582; this version posted May 20, 2020. The copyright holder for this preprint (which was not certified by peer review) is the author/funder, who has granted bioRxiv a license to display the preprint in perpetuity. It is made available under aCC-BY-NC-ND 4.0 International license.

imaging of nascent presynaptic boutons (defined as vGlut1 positive puncta) and mitochondria (marked with mito-DsRed) over 24 hours periods in 5-7DIV
PNs (Fig. S3A-B). To alleviate phototoxicity while preserving spatio-temporal dynamics, we performed pulses of high-frequency imaging (5 minutes at 12
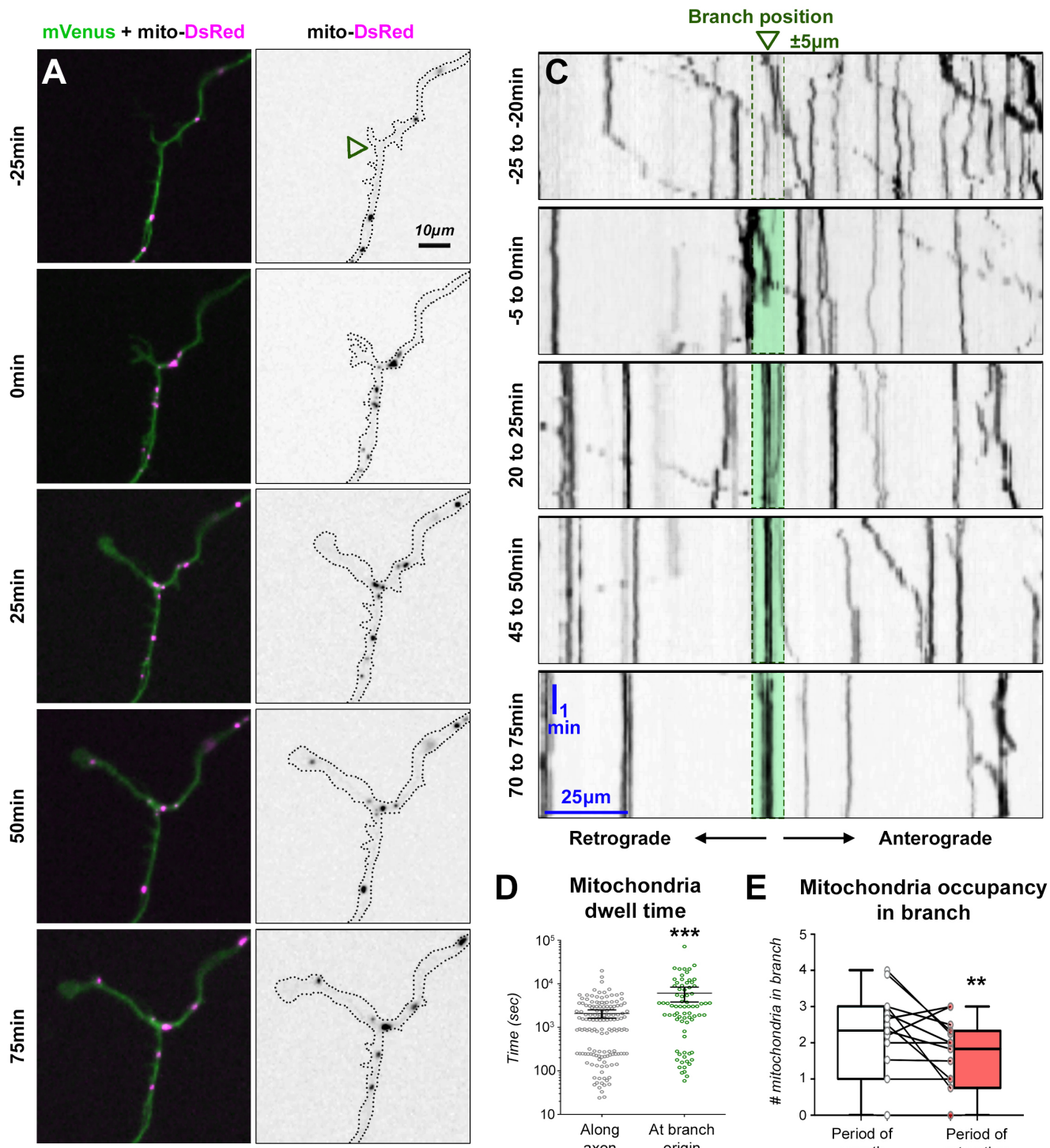

B Mitochondria recruitment at branchpoints

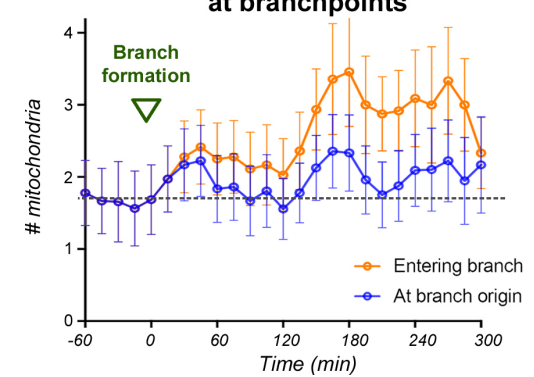

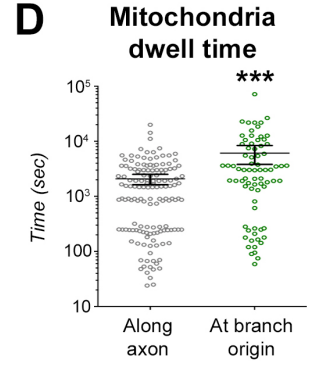

$\mathbf{F}$

Branch lifetime

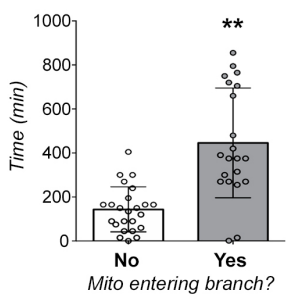

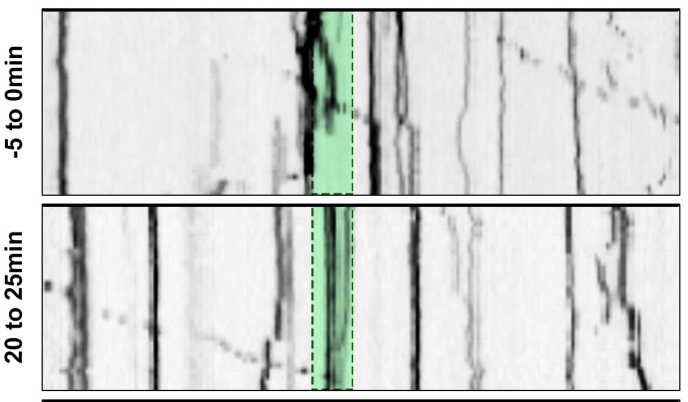
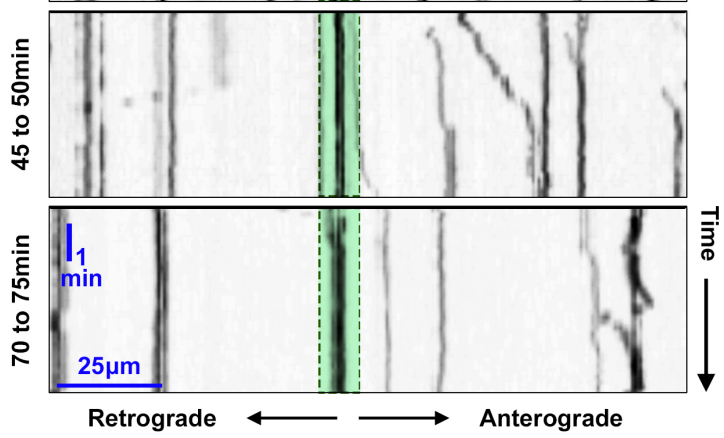

E Mitochondria occupancy

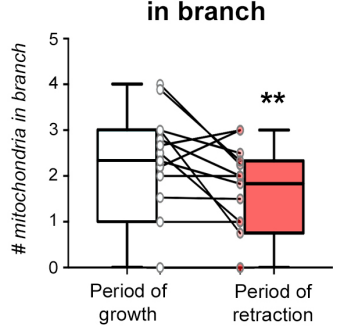

$\mathbf{G}$

Branch length

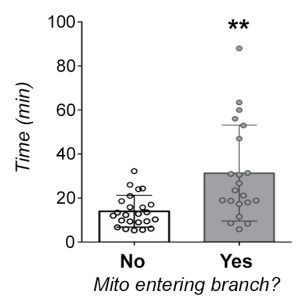

Figure 3: dynamics of mitochondria recruitment at branch origin and inside branches

(A) Time-lapse imaging of a spontaneous branch formation from the axon of a cortical PN at 5DIV following EVCE of mVenus (green) and mito-DsRed (magenta) coding plasmids. Branch apparition defined by length $>5 \mu \mathrm{m}$ and a growth-cone like structure was considered $\mathrm{T}=0 \mathrm{~min}$. (B) Dynamics of mitochondria recruitment at branch origin (blue) or at branch origin and inside branch (orange) over time. Data: average $\pm \mathrm{SEM}, \mathrm{N}=12$ axons. (C) Kymographs of axonal mitochondria centered around branch position (green arrowhead) from axon in (A).

(D) Mitochondria dwell time at branch origin $( \pm 5 \mu \mathrm{m})$ compared to dwell time along the axon. Time was represented on a logarithmic scale. Each point represents a mitochondrion. $\mathrm{N}_{\text {(along axon) }}=143, \mathrm{~N}_{\text {(branch origin) }}=75$ out of 14 axons. Bars: median $\pm 95 \%$ Cl. Statistical test: MannWhitney.

(E) Comparison of mitochondria occupancy in a branch during periods of growth (white) or retraction (red). Box-plot: $75^{\text {th }}$ percentile, median and $25^{\text {th }}$ percentile. Individual dots represent average over period (per branch), $\mathrm{N}=15$ branches. Statistical test: Wilcoxon matched-pairs ranked test.

$(F-G)$ Correlation of mitochondria entry into a branch with lifetime $(F)$ and length $(G)$. Bars: median $\pm 95 \%$ Cl. Each dot represents a spontaneous branch formation event. $\mathrm{N}_{(\mathrm{No})}=24 ; \mathrm{N}_{(\text {Yes }}=21$. Statistical test: Mann-Whitney 
frames per minute) followed by periods with low frequency imaging (20 minutes at 0.1 frames per minute). We detected 45 events of spontaneous branch formation over 24 neurons and quantified presynaptic boutons and mitochondria localization at branchpoints and within branches, as well as axonal branch length and lifetime.

Studies in the Xenopus and Zebrafish demonstrated that axonal collateral branches from RGC neurons originate from presynaptic sites (Javaherian and Cline, 2005; Meyer and Smith, 2006; Ruthazer et al., 2006). We confirmed some of these findings in mouse cortical PNs (Fig. S3C): time-lapse longitudinal imaging revealed that presynaptic boutons form along the axon before the formation of collateral branches. Furthermore, these presynaptic boutons remained stable at branch origin and additional vGlut1 clusters formed inside the branch as it consolidates.

In mouse sensory axons, mitochondria recruitment at sites of local protein synthesis promote filopodia and branch formation (Spillane et al., 2013). However, in cortical PNs, we observed that mitochondria were recruited to branchpoints after, and not prior to, branch formation (Fig. 3A and Fig. S3D). Immediately following the turning of filopodia to new axonal branches (as defined by the formation of a growth-cone like structure, $\mathrm{T}=0 \mathrm{~min}$ ), mitochondria started clustering at branch origin. On average the number of mitochondria increased by $42 \%$ at branchpoints within 30 minutes of branch formation (Fig. 3B). In parallel we assessed local changes in mitochondria motility around axonal branch points (Fig. 3C). Following branch formation, we observed clustering of immobile mitochondria within $5 \mu \mathrm{m}$ of branch origin (green box in Fig. 3C). In contrast, mitochondria passing in the corresponding region of the axon before branch formation only displayed short dwelling periods. Individual mitochondria dwell time at branch origin was significantly longer than at other positions along the axon (Fig. 3D).

Furthermore, we observed that mitochondria entered newly formed collateral branches shortly after clustering at branch origin (Fig. 3A, T=50min and Fig. S3D). Within 2 hours of branch formation, there was a marked increase of mitochondria entering branches (Fig. 3B). The number of mitochondria inside branches was correlated with periods of extension and decreased when branches were retracting (Fig. 3E). Accordingly, mitochondria entering branches were correlated with increased length and lifetime (Fig. 3F-G). On the contrary branches that failed to recruit mitochondria rapidly retracted (Fig. S3E). Overall, our results demonstrate that contrary to sensory axons, branch formation precedes mitochondria clustering but also revealed that mitochondria are involved in axonal branch stabilization in mouse cortical PNs.

\section{Mitochondria are required for branch stabilization}

We next tested how the local pool of mitochondria is required for branch stabilization by performing Chromophore-Assisted Light Inactivation (CALI) of mitochondria (Bulina et al., 2006a; 2006b). As a proof of principle, we co-expressed the geneticallyencoded photosensitizer Killer-Red (mito-KR) (Bulina et al., 2006b; 2006a) targeted to the mitochondrial matrix together with the biosensor mito-roGFP2 (Gutscher et al., 2008) to measure ROS production in mitochondria following photosensitization in HeLa cells. Following a single $30 \mathrm{sec}$ laser pulse, mito-KR induced a strong production of ROS in mitochondria restricted to the laser-targeted Region Of Interest (ROI) (Fig. S4A-D). Furthermore, CALI led to a rapid fragmentation of mitochondria in the ROI (Fig. S4EG). We observed no change in roGFP2 signal in the cytosol even 30 minutes following CALI, suggesting minimal ROS leakage from damaged mitochondria (Fig. S4H). CALI on control fluorescent protein mtDsRed did not induce significant morphological changes in mitochondria or accumulation of ROS (Fig. S4D-G).

We subsequently expressed mito-KR in cortical PNs by EVCE and targeted axonal mitochondria for photosensitization. As observed in HeLa cells, a $30 \mathrm{sec}$ laser pulse induced a rapid accumulation of ROS in mitochondria, restricted to the ROI (Fig. 4AB). We then assessed the local metabolic consequences of axonal CALI by expressing PercevalHR, a genetically-encoded biosensor for the ATP:ADP ratio. Following laser illumination of mito$K R$, we measured an immediate drop in PercevalHR signal, indicating a local decrease of the ATP:ADP ratio (Fig. 4C). The reduction in PercevalHR signal was persistent over 60 minutes and largely restricted to the ROI (Fig. 4D-E). In contrast PercevalHR signal was not affected by laser illumination upon expression of control mt-DsRed (Fig. 4F).

Finally, we expressed mito-KR together with the green fluorescent protein mVenus by IUCE and observed axon morphogenesis over 12 hours timelapse movies (Fig. 4G). Localized photoinactivation of mitochondria significantly altered branch dynamics in the ROI, by promoting branch retraction and decreasing branch growth, whereas this effect was not observed on the same axon outside of the ROI, indicating that overall axonal viability is not affected. In contrast, laser illumination had little effect on branch dynamics upon expression of mt-DsRed (Fig. 4H-K). Taken together, our results demonstrate that 
bioRxiv preprint doi: https://doi.org/10.1101/2020.05.18.102582; this version posted May 20, 2020. The copyright holder for this preprint (which was not certified by peer review) is the author/funder, who has granted bioRxiv a license to display the preprint in perpetuity. It is made available under aCC-BY-NC-ND 4.0 International license.
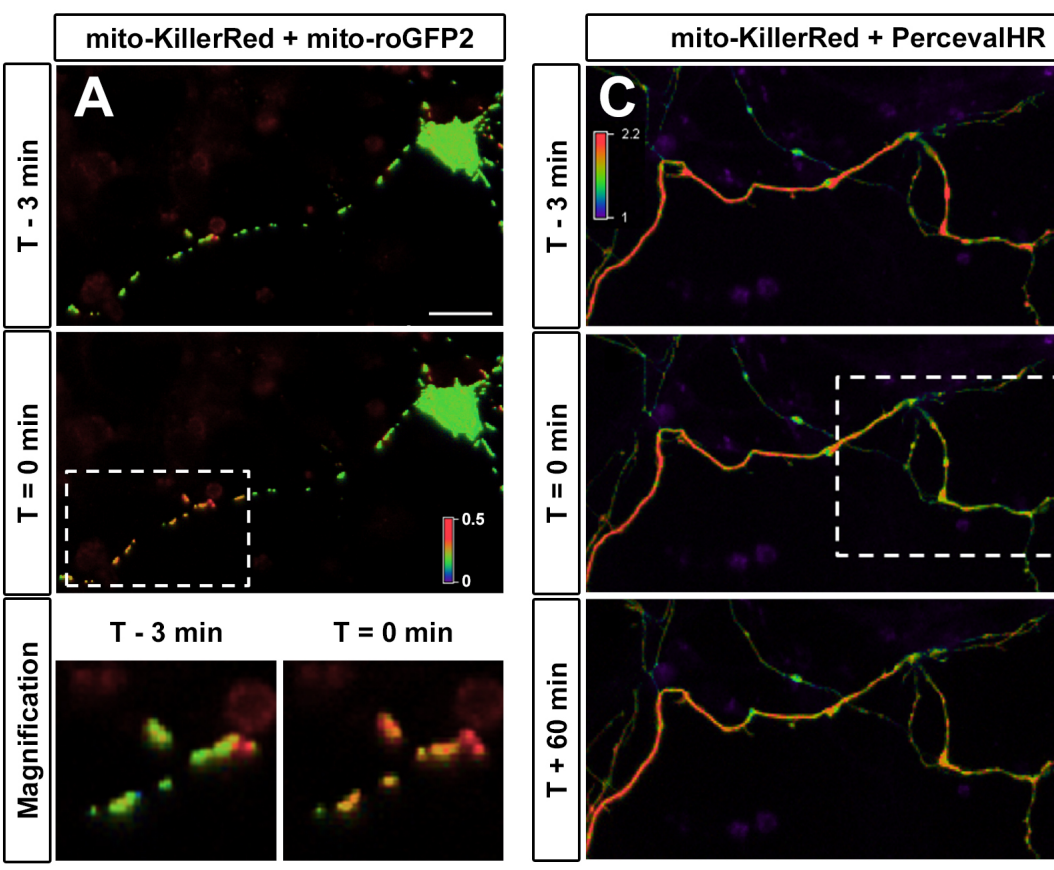

B Mitochondrial ROS (mito-KillerRed)

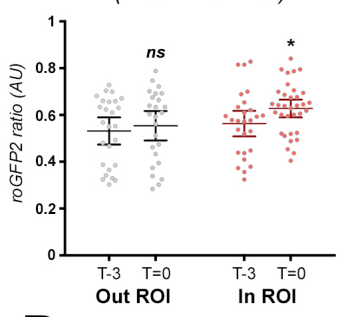

D
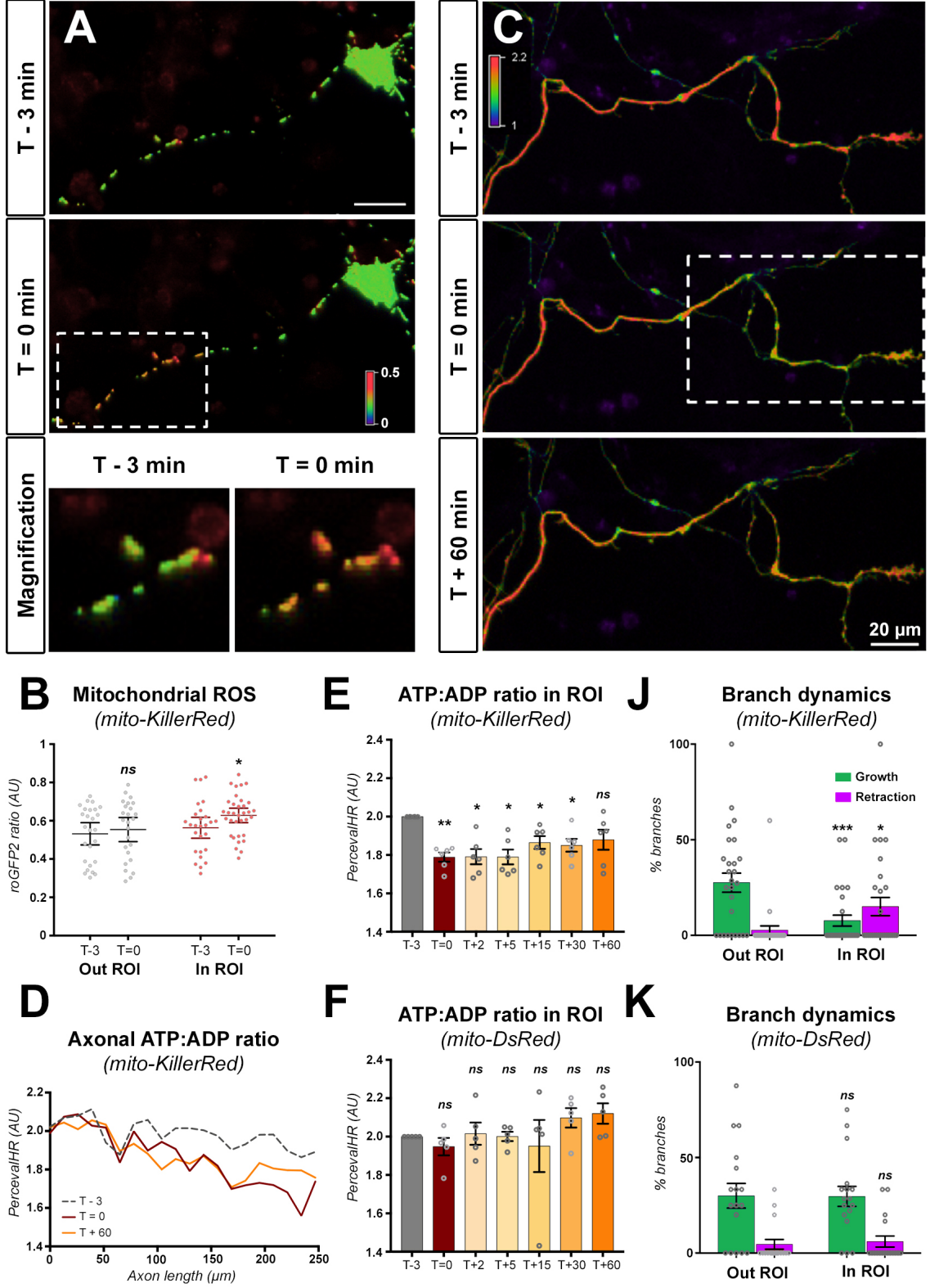

$\mathbf{F}$
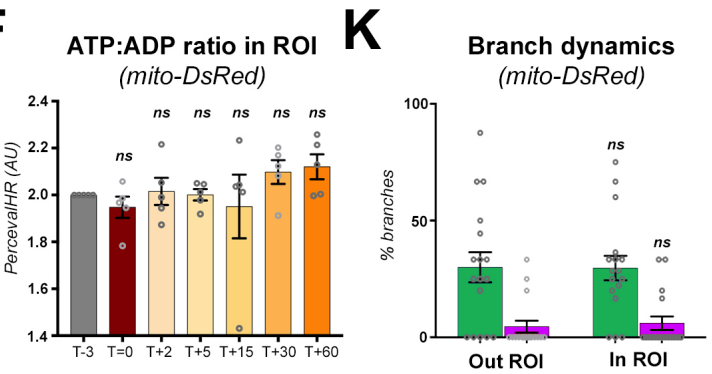
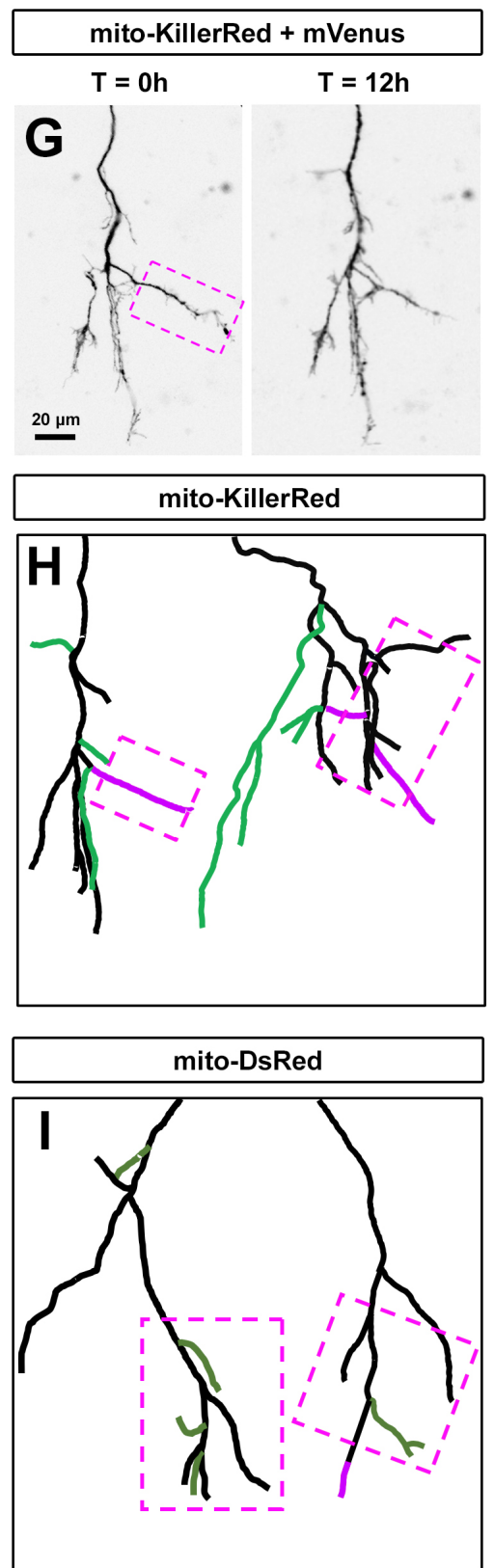

Figure 4: mitochondria CALI disrupts branch stabilization

(A) Typical neuron at 5DIV expressing mt-KR. At T=0min, CALI was performed by a 30sec laser pulse in the Region of Interest (ROI, white box). ROS was measured by mito-roGFP2 fluorescence (red = oxidized, blue = reduced). (B) Mitochondria ROS accumulation was measured outside and inside of the ROI before and immediately after CALI. Each point represents roGFP2 signal (Ex405:Ex488 ratio, see methods) for a given mitochondrion. Bars: average $\pm 95 \% \mathrm{Cl}$. Analysis: Unpaired t-test. $\mathrm{N}_{(\mathrm{T}-3, \text { oUT })}=26, \mathrm{~N}_{(\mathrm{T}=0, \text { oUT })}=25, \mathrm{~N}_{(\mathrm{T}-3, \mathrm{IN})}=27, \mathrm{~N}_{(\mathrm{T}=0, \mathrm{IN})}=34$ mitochondria out of 7 independent experiments.

(C) Measurement of the ATP:ADP ratio with PercevalHR in the axon of cortical PNs expressing mt-KR. CALI was performed in the indicated ROI (white box). (D) PercevalHR signal (Ex488:Ex405 ratio, see methods) was measured along the axon in (C) at the indicated time-points. (E-F) Average PercevalHR signal in the ROI of neurons expressing mt-KR or the control mt-DsRed. Bars: average \pm SEM. Analysis: Repeated measures ANOVA with Dunnett's multiple comparison test. $\mathrm{N}=5$ axons out of 5 independent experiments.

(G) Time-lapse imaging of axon growth over 12 hours following CALI (magenta box). mVenus fluorescence was used to assess axonal morphology. ( $\mathrm{H}-\mathrm{I})$ Examples of axon (schematic reconstruction) expressing mt-KR or the control mt-DsRed. Growing/new branches (green) and retracting branches (magenta) were observed over 12 hours and quantified in and out of the ROI (J-K). Bars: average \pm SEM. Analysis: 2 way ANOVA with Bonferroni's multiple comparison test. Growth or retraction in ROI was compared to out ROI. NkillerRed $=27$ axons, NDsRed=17 axons out of 4 independent experiments.

mitochondria are required locally to promote branch stabilization.

\section{NUAK1 kinase controls axonal mitochondrial metabolism}

The observation that mitochondrial metabolism is necessary and sufficient to promote collateral branching (Fig. 1) and that mitochondria are required locally for axonal branch stabilization (Fig. 3) raises the question of their local function. We previously reported that the Serine/Threonine kinase NUAK1 controls terminal axon branching through the control of mitochondria capture at presynaptic sites in developing PNs (J. Courchet et al., 2013). 
bioRxiv preprint doi: https://doi.org/10.1101/2020.05.18.102582; this version posted May 20, 2020. The copyright holder for this preprint (which was not certified by peer review) is the author/funder, who has granted bioRxiv a license to display the preprint in perpetuity. It is made available under aCC-BY-NC-ND 4.0 International license.

A

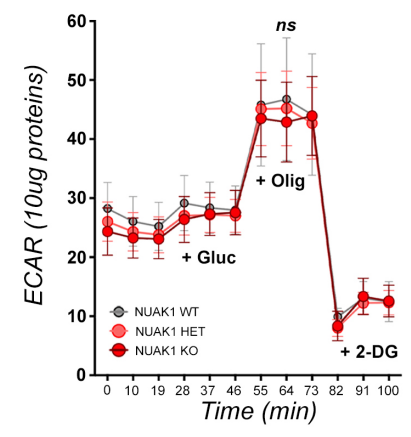

B

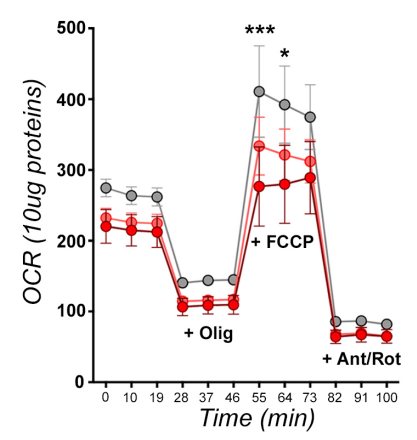

F PercevalHR

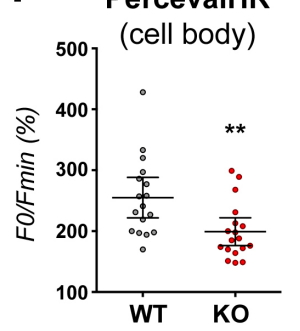

\section{H}
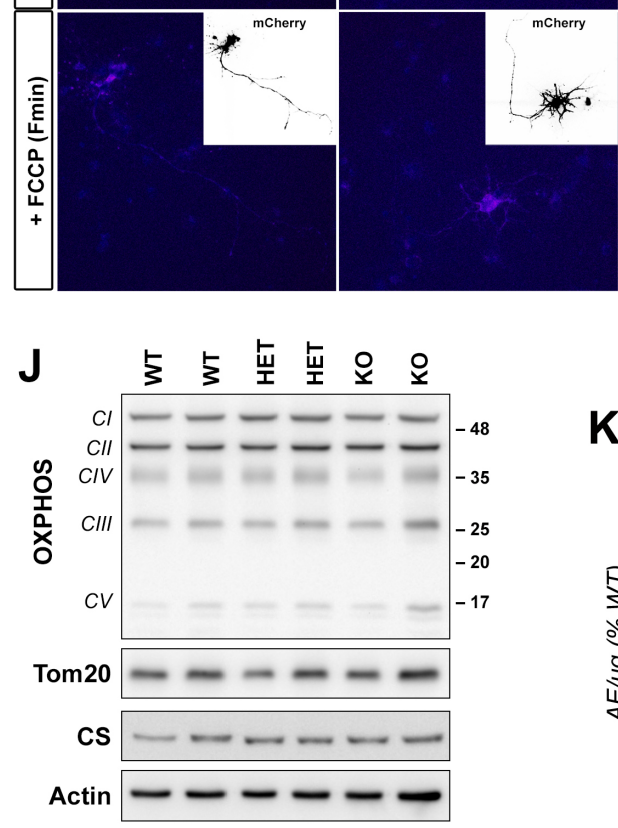

C

Mitochondria DNA

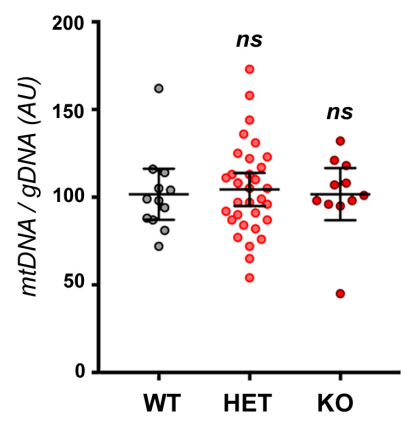

G

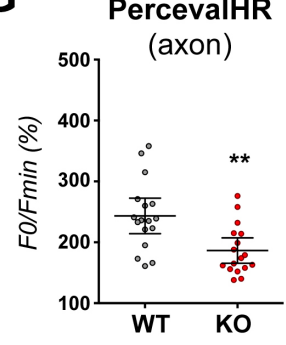

Redox potential

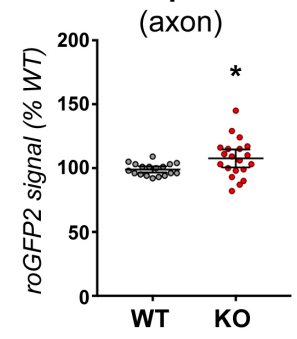

$\mathbf{L}$

SDH activity

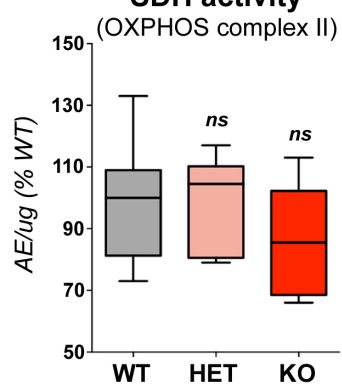

Figure 5: mitochondrial metabolism is altered in NUAK1-deficient neurons

(A-B) Measurement of glucose metabolism in 5DIV cortical neurons cultures from the indicated genotypes. ExtraCellular Acidification Rate (ECAR) and Oxygen Consumption Rate (OCR) were measured respectively to assess glycolysis and oxidative metabolism. Data: average \pm SEM. $N_{W T}=9, N_{\text {HET }}=27, N_{K O}=9$.

(C) Measurement of mitochondrial content in cortical neurons cultures of the indicated genotypes. Mitochondrial and genomic DNA was measured by quantitative PCR. Each point represents a distinct culture. Bars: average $\pm 95 \% \mathrm{Cl}$. Analysis: Kruskal-Wallis test with Dunn's post-test. $\mathrm{N}_{(\mathrm{WT})}=12, \mathrm{~N}_{(\mathrm{HET})}=32, \mathrm{~N}_{(\mathrm{KO})}=11$.

(D-E) Measurement of the ATP:ADP ratio in 5DIV NUAK1 $1^{\mathrm{F} / F}$ neurons transfected with a control (D) or a CRE coding plasmid (E). Excerpt: mCherry fluorescence was used to determine neuronal morphophogy. PercevalHR signal is displayed as a fluorescence ratio between 488 and 405 illumination using a Fire LUT (White: high ratio. Blue: low ratio)

(F-G) Measurement of the ATP:ADP ratio in NUAK1 $1^{\mathrm{FF}}$ neurons expressing a control (WT) or CRE-expressing plasmid (KO). Each point represents average values for a given neuron. Bars: average $\pm 95 \% \mathrm{Cl}$. $\mathrm{N}_{(\mathrm{WT})}=18, \mathrm{~N}_{(\mathrm{KO})}=18$ out of 3 independent experiments.

$(\mathrm{H}-\mathrm{I})$ Measurement of the mitochondrial membrane potential $(\Delta \Psi \mathrm{m})$ or redox potential (GRX1-roGFP2) in the axon of NUAK1 ${ }^{\mathrm{FF}}$ neurons expressing a control (WT) or CRE-expressing plasmid (KO). Each point represents average values for a given neuron. Bars: average \pm $95 \% \mathrm{Cl}$. Analysis: Unpaired t-test with Welch's correction. (H) $N_{(\mathrm{WT})}=24, \mathrm{~N}_{(\mathrm{KO})}=27$ out of 5 independent experiments. $(\mathrm{I}) \mathrm{N}_{(\mathrm{WT})}=18, \mathrm{~N}_{(\mathrm{KO})}=20$ out of 4 independent experiments.

(J) Typical Western-blot showing the expression of OXPHOS proteins in mitochondria from cortical neuronal cultures of the indicated genotypes.

(K-L) SDH and CS enzymatic activity relative to protein quantity (normalized to WT). Box-plot: 75 th percentile, median and 25 th percentile. Analysis: One-way ANOVA with Dunnett's multiple comparison test. $\mathrm{N}_{(\mathrm{WT})}=13, \mathrm{~N}_{(\mathrm{HET})}=8, \mathrm{~N}_{(\mathrm{KO})}=10$ independent samples.

Interestingly NUAK1, a kinase related to the master metabolic regulator AMPK (Lizcano et al., 2004) is also involved in mitochondrial metabolism in c-Myc dependent cancer models (Liu et al., 2012). We therefore sought whether NUAK1 controls mitochondrial function as well in cortical PNs. Using 
a Seahorse analyzer, we measured the glycolytic and respiratory capacity of 7 DIV neuronal cultures from NUAK1 $1^{++}(\mathrm{WT}), \mathrm{NUAK}^{+/-}(\mathrm{HET})$ or NUAK1/-- neurons (KO). There was a dose-response decrease in both the basal and maximal respiratory rate upon deletion of NUAK1, whereas glycolysis was largely unaffected (Fig. 5A-B). Importantly there was no difference in mitochondrial DNA content in NUAK1 KO neuronal cultures compared to WT conditions, thus ruling out that the decreased respiratory rate is a secondary consequence of impaired mitochondria biogenesis (Fig. 5C). To confirm these results, we assessed the overall metabolic consequence of NUAK1 knockout by measuring the ATP:ADP ratio with the biosensor PercevalHR. In 5DIV neuronal cultures following EVCE of plasmids encoding CRE together with PercevalHR, we observed a marked decrease of the ATP:ADP ratio in NUAK1 KO neurons (Fig. 5D-E). After quantification, the average PercevalHR signal was decreased by $21,9 \%$ in NUAK1 KO neurons compared to control cortical PNs (Fig. 5F). Interestingly, the decrease in PercevalHR signal was even more pronounced in the axon of NUAK1 KO neurons (-23.4\%) (Fig. 5G).

The decreased respiratory rate suggested that NUAK1 is required not only for mitochondria trafficking, but also for proper mitochondria function in axons. To test this hypothesis, we turned to microscopy-based strategies to directly investigate mitochondrial function. Cortical neuron cultures were performed from floxed NUAK1 embryos (NUAK1 ${ }^{\mathrm{F} / F}$; (V. Courchet et al., 2018)) in order to achieve sparse, single-cell NUAK1 inactivation. CRE recombinase encoding plasmids were electroporated together with plasmids encoding the fluorescent protein mVenus and the mitochondrial marker mito-BFP. At 5DIV, cultures were exposed to Tetra-Methyl-Rhodamine Ethyl-ester (TMRE) to measure mitochondrial inner membrane potential $\left(\Psi_{\mathrm{m}}\right)$. We observed a marked decrease of $\Psi_{\mathrm{m}}$ in the axon of NUAK1 KO neurons, compared to control cortical PNs electroporated with a non-CRE expressing plasmid (Fig. $\mathbf{5 H}$ and Fig. S5A). In parallel, we measured axonal mitochondrial redox potential using a mitochondria-targeted roGFP2. We observed a shift of roGFP2 signal toward a more oxidized state in NUAK1 KO neurons, suggesting an increased ROS production by axonal mitochondria (Fig. $5 \mathrm{I}$ and Fig. S5B).

To check whether the low $\Psi_{m}$ and oxidized mitochondria state is a secondary consequence of the increased trafficking of NUAK1 KO neurons, we measured TMRE and roGFP2 fluorescence in wildtype neuronal cultures and sorted out motile versus stationary mitochondria (Fig. S5C-F), however there was no difference in either measured parameter.
Altogether, our results strongly argue that mitochondria function is decoupled from mitochondria trafficking in the axon and therefore suggest that NUAK1 regulates not only presynaptic mitochondria capture but also mitochondrial metabolic function.

Finally, we turned to biochemical assays to determine if mitochondria are defective per se or if mitochondria impairment is context-dependent. Specifically we sought to confirm that the alterations in mitochondrial metabolism resulting from NUAK1 loss are conserved in an in vivo setting. We measured the activity of two key mitochondrial enzymes, Citrate Synthase (CS), a key enzyme of the Citric Acid Cycle, and of Succinate Dehydrogenase (SDH), forming the complex II of the mitochondrial respiratory chain. We observed a marked, dose-dependent reduction of CS from mitochondria extracted of the cortex of NUAK1 KO mice (Fig. 5K). We measured a similar, although not statistically significant, reduction in SDH activity from NUAK1 KO cortices (Fig. 5L). As a control, we checked the expression of OXPHOS supercomplexes and CS by Western-blot but observed no change with NUAK1 expression (Fig. 5J).

Taken together, our results indicate that NUAK1 controls not only mitochondria positioning but also mitochondria function along the axon and suggest that a metabolic imbalance may account for the axon branching phenotype of NUAK1 KO neurons.

\section{Upregulation of mitochondria function rescues collateral branching}

In order to determine if there is a direct, causal, link between the downregulation of mitochondrial metabolic activity and the reduction in collateral branching in NUAK1 KO axons, we devised strategies to upregulate mitochondria function. Our prediction was that, improving mitochondrial fitness should rescue collateral branching in NUAK1 deficient neurons. Based on published studies, we treated cortical PNs with the cell-permeant mitochondria modulator L-Carnitine (Dickey and Strack, 2011; Sainath et al., 2017), a cell-permeant, lysine-derived quaternary amine that acts by promoting the metabolism of long-chain fatty acids by the mitochondria. It has been shown to be neuroprotective in a wide variety of metabolic stresses (Tefera and Borges, 2016; Zanelli et al., 2005) and has clinical interest in the treatment of depression and anxiety (Chiechio et al., 2017; Filiou and Sandi, 2019).

We achieved single-cell knockout of NUAK1 through EVCE of CRE-coding plasmid in NUAK1 ${ }^{\text {F/F }}$ cortical 

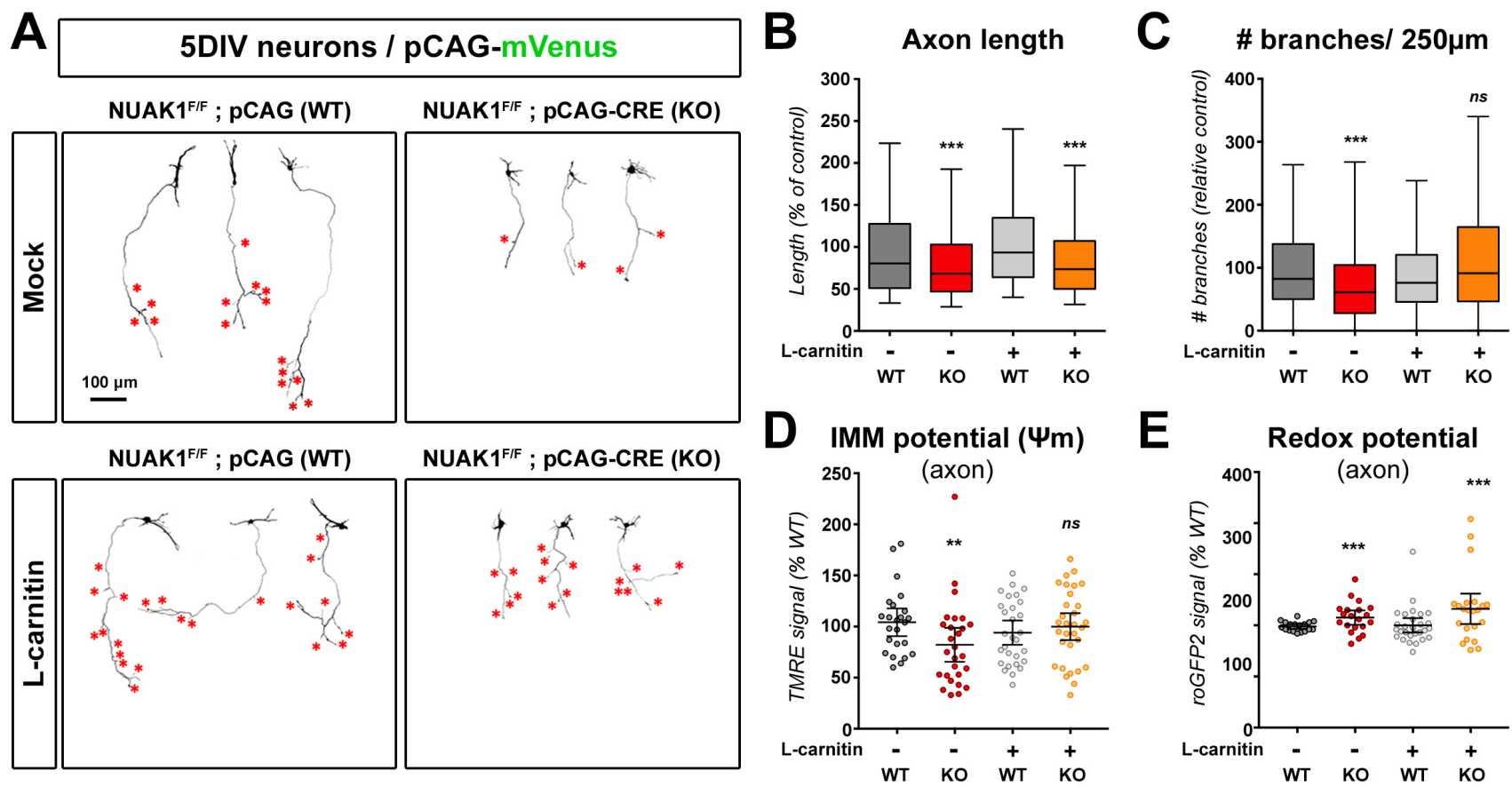

Figure 6: upregulation of mitochondrial function rescues axon branching in NUAK1-deficient neurons

(A) Representative images of mVenus expressing cortical neurons of NUAK1F/F background and electroporated with a control or CRE-coding plasmid. At DIV2 neurons were treated with L-Carnitine $(1 \mathrm{mM})$. Red stars indicate collateral branches.

(B-C) Quantification of axon length and collateral branches of 5DIV neurons in the indicated conditions. Box-plot: $75^{\text {th }}$ percentile, median and $25^{\text {th }}$ percentile. Statistical tests: Kruskal-Wallis test with Dunn's post-test (each condition compared to untreated WT condition). $\mathrm{N}_{(\mathrm{WT})}=399$, $\mathrm{N}_{(\mathrm{KO})}=232, \mathrm{~N}_{(\mathrm{WT}+\mathrm{L}-\mathrm{Carn})}=387, \mathrm{~N}_{(\mathrm{KO}+\mathrm{L}-\mathrm{Carn})}=256$ out of 5 independent experiments.

$(D-E)$ Effect of L-Carnitine on the mitochondrial membrane potential $(\Delta \Psi \mathrm{m})$ and redox potential of WT and KO neurons. Untreated samples from experiment in Figure 5D-E. Each point represents average values for a given neuron. Bars: average $\pm 95 \% \mathrm{Cl}$. Analysis: Unpaired t-test with Welch's correction. (D) $\mathrm{N}_{(\mathrm{WT}+\mathrm{L}-\mathrm{Carn})}=29, \mathrm{~N}_{(\mathrm{KO}+\mathrm{L}-\mathrm{Carn})}=31$ out of 5 independent experiments. (E) $\mathrm{N}_{(\mathrm{WT}+\mathrm{L}-\mathrm{Carn})}=28, \mathrm{~N}_{(\mathrm{KO}+\mathrm{L}-\mathrm{Carn})}=22$ out of 4 independent experiments.

PNs and quantified axon morphology at 5DIV. As previously reported (J. Courchet et al., 2013) NUAK1null neurons had shorter axons (Fig. 6A) with a reduced number of collateral branches (red stars in Fig. 6A). Upon L-Carnitine addition to the culture medium, we observed no effects on axon length in control or NUAK1-null cortical PNs (Fig. 6B). In contrast, L-Carnitine addition to NUAK1-deficient neurons (but not control) increased collateral branch formation compared to untreated control or NUAK1deficient neurons. When normalized to axonal length, L-Carnitine induced a complete rescue of collateral branches, without affecting axon elongation (Fig. 6BC). Importantly, L-Carnitine treatment had no effect on wild-type neurons. As an alternative means to upregulate mitochondrial function, we treated neuronal cultures with the mitochondria-targeted electron carrier Vitamin K2/menaquinone (VK2) (Vos et al., 2012). Similar to the effect of L-Carnitine, we observed a normalization of axonal branching in NUAK1-deficient neurons without affecting axonal length in VK2 treated neurons (Fig. S6A-B).

We next sought to confirm that L-Carnitine treatment upregulated mitochondrial function in NUAK1-null neurons. We turned to microscopy-based assays using TMRE to measure $\Psi_{\mathrm{m}}$ in 5DIV neuronal cultures. L-Carnitine treatment normalized $\Psi_{\mathrm{m}}$ in NUAK1 KO neurons (Fig. 6D), indicating an upregulation of mitochondrial fitness. Interestingly, L-Carnitine had no effect on mitochondrial redox potential and failed to rescue the increased mito-roGFP2 signal in NUAK1-null neurons (Fig. 6E), thus ruling out that LCarnitine rescues axonal branching through ROS scavenging. Accordingly, application of the ROS scavenger $\mathrm{N}$-AcetylCystein (N-AC) had no effect on axon branching despite the normalization of oxidative stress in treated neurons (Fig. S6C-E).

\section{L-Carnitine rescues terminal axon branching in NUAK1 KO in vivo}

Finally, we performed experiments to determine if metabolic upregulation can rescue terminal axon branching in NUAK1 KO mice in vivo. Our choice turned toward L-Carnitine because it presented several advantages: first it is virtually not toxic and especially it is used in humans for treatment in newborn babies to treat metabolic disorders and carnitine deficiency. Second, it is suitable for oral administration, and has been approved for use in veterinary medicine. We performed a conditional inactivation of NUAK 1 in the dorsal telencephalon by breeding with the Nex ${ }^{\mathrm{CRE}}$ mouse line (Goebbels et al., 2006) to induce cortex-specific post-mitotic deletion in all cortical PNs. We previously demonstrated that 


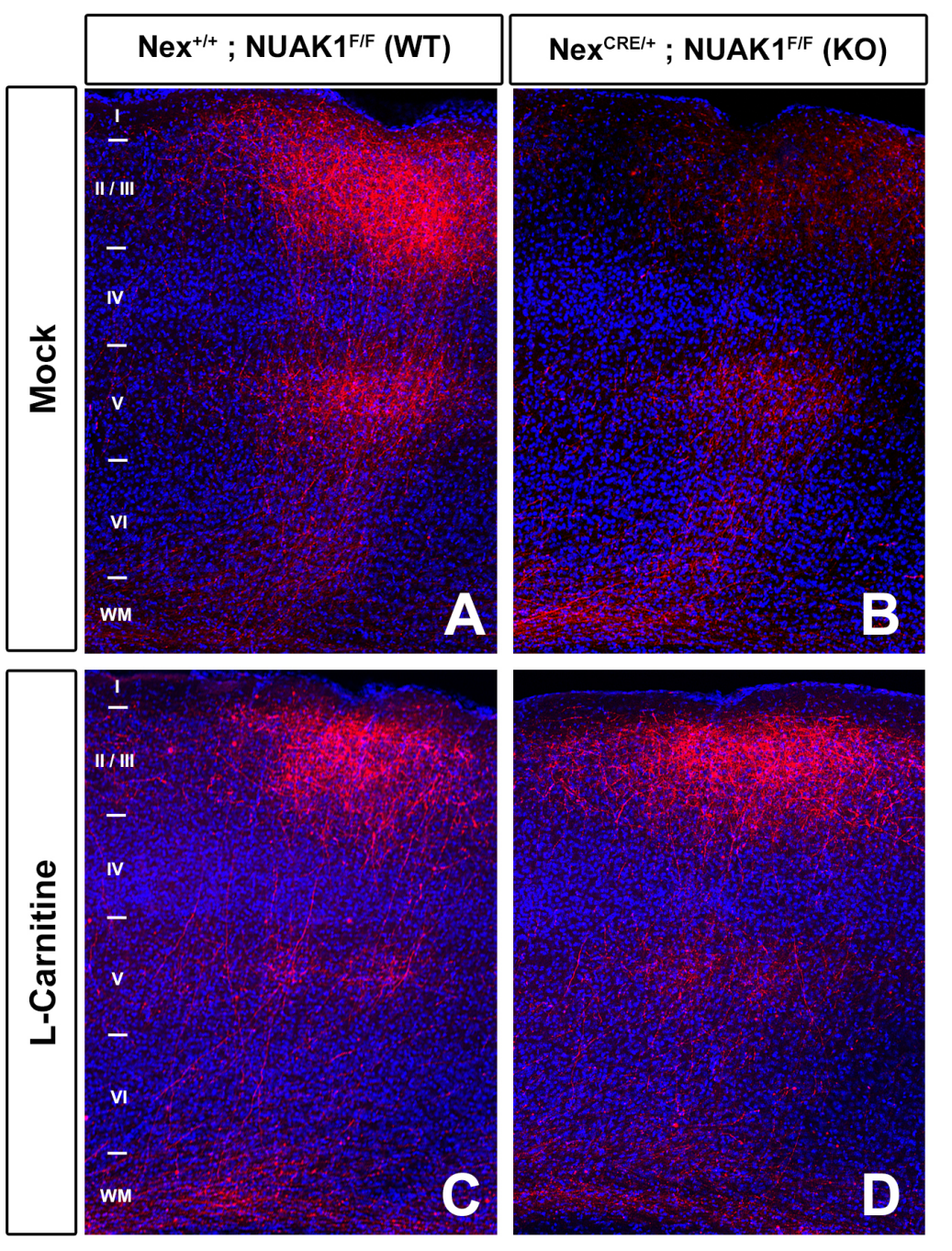

Hoechst / mScarlet-i
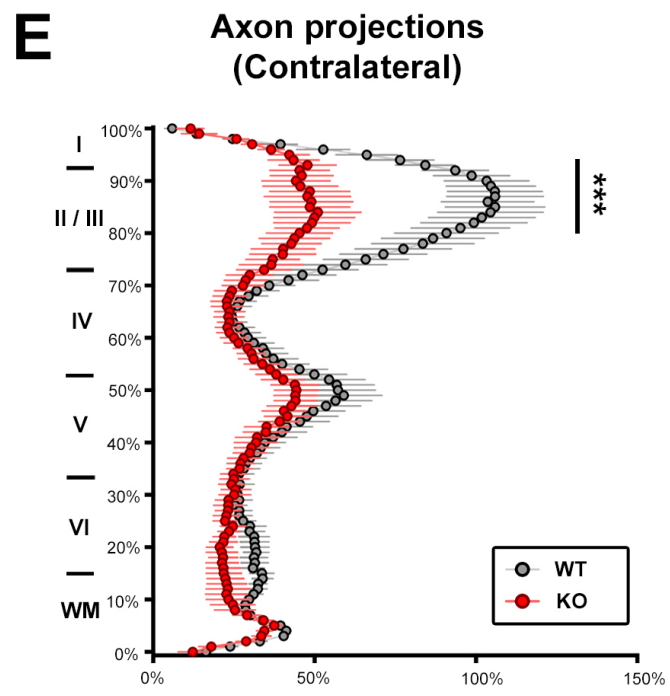

$\mathbf{F}$

Signal intensity (\%)

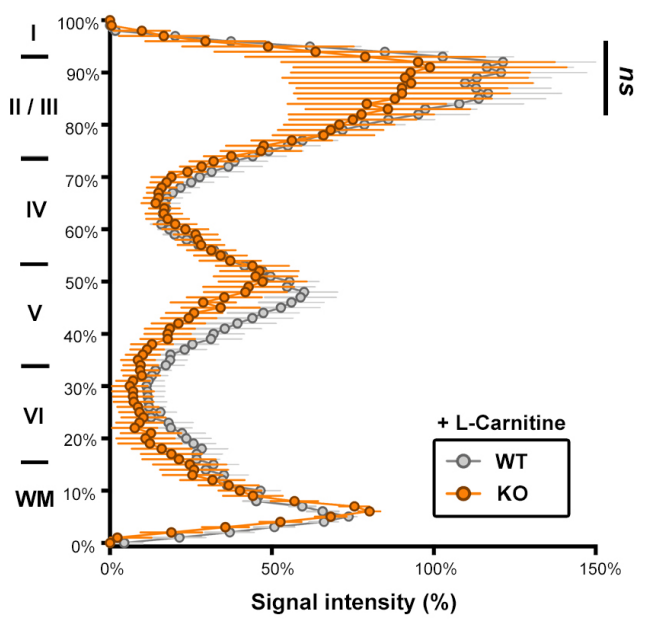

Figure 7: L-Carnitine treatment rescues terminal axon branching in vivo

(A-D) Representative images of contralateral terminal axon branching in NexCRE ; NUAK1 mice following IUCE with a plasmid coding the red fluorescent protein $\mathrm{mScarlet-I.} \mathrm{When} \mathrm{indicated} \mathrm{(C-D)} \mathrm{animals} \mathrm{were} \mathrm{treated} \mathrm{with} \mathrm{L-Carnitine} \mathrm{in} \mathrm{drinking} \mathrm{water.} \mathrm{The} \mathrm{observed} \mathrm{decrease} \mathrm{in} \mathrm{terminal}$ axon branching in $\mathrm{KO}$ animals (B) was rescued upon L-Carnitine treatment (D).

$(E-F)$ Quantification of normalized mScarlet-i fluorescence along a radial axis in the contralateral cortex. Data: Average \pm SEM. Statistical tests: Two-way ANOVA with Bonferroni's multiple comparison. $\mathrm{N}_{\mathrm{WT}}=8, \mathrm{~N}_{\mathrm{KO}}=6, \mathrm{~N}_{\mathrm{WT}+\mathrm{L}-\mathrm{CAR}}=10, \mathrm{~N}_{\mathrm{KO}+\mathrm{L}-\mathrm{CAR}}=6$

this conditional genomic deletion leads to a significant decrease in terminal axon branching of contralaterally-projecting layer $2 / 3$ axons (V. Courchet et al., 2018). Upon detection of gestation (at E13.5), time pregnant mice were treated with LCarnitine in the drinking water, while the control group received only regular water. At E15.5, we performed In Utero Cortical Electroporation (IUCE) of plasmid coding the red fluorescent protein mScarlet-I as a neuronal cell filler (Bindels et al., 2017). Drug treatment was continued after birth and during lactation, and pups were sacrificed at weaning (P21) when cortical layer 2/3 PNs axons display adult-like branching patterns (Fig. 7).

As expected, we could observe a decrease in terminal axon branching in $\mathrm{KO}$ mice $\left(\mathrm{Nex}{ }^{\mathrm{CRE} /+} ; \mathrm{NUAK} 1^{\mathrm{F} / \mathrm{F}}\right)$ compared to controls $\left(\mathrm{Nex}^{+/+} ; \mathrm{NUAK} 1^{\mathrm{F} / F}\right)$ (Fig. 7A-B). On the contrary, terminal axon branching was undistinguishable between WT and KO mice upon L-Carnitine treatment (Fig. 7C-D). Quantification confirmed that L-Carnitine treatment during pregnancy and lactation is sufficient to rescue axon branching, especially in contralateral layer 2/3 (Fig. 7E-F). Taken together, our results suggest that metabolic upregulation of mitochondrial function can rescue defective axon branching in NUAK1 deficient mice in vivo.

\section{DISCUSSION}

In the present study, we extended our previous observations that mitochondria distribution in the axon is necessary and sufficient for terminal branching, by providing new evidence that mitochondria positioning at axonal branch points and mitochondria function locally supports branch stabilization. We characterized that mitochondria capture at presynaptic boutons occurs preferentially 
at boutons associated with axonal branch points. Finally, we observed that the AMPK-related kinase NUAK1 controls not only axonal mitochondria distribution but also mitochondrial function and that upregulation of mitochondrial metabolism is sufficient to rescue the axonal branching defects characterizing NUAK1-deficient axons in vitro and in vivo. Together our results suggest a two-hit model by which it is equally important to ensure that mitochondria reach their proper destination, but also that they are active locally, to stabilize nascent axonal branches.

One striking observation from our study is the fact that axon elongation and collateral branching are operatively decorrelated in terms of metabolic requirement. First, we observed a dose-response effect of D-glucose concentration on axon length, whereas collaterals formation could be supported in an all-or-nothing fashion by directly fueling mitochondrial metabolism (Fig 1). Furthermore LCarnitine and VK2 can rescue axon branching in a NUAK1 null background, without affecting significantly axon length (Fig 6). We previously reported that an autism-linked truncated NUAK1 impairs axon branching without affecting axon elongation (V. Courchet et al., 2018), although mitochondrial function has not been explored for this mutant. Taken together these observations suggest that, in cortical axons, mitochondrial function is necessary and sufficient for collateral branching. Further studies are warranted to determine if axon elongation involves distinct metabolic pathways, and if so whether these are also dependent upon NUAK1 function.

Several lines of evidence support the idea that immature neurons differ significantly from synaptically active neurons in terms of their metabolic organization. Axonal transport of mitochondria plays a critical role in supporting axon morphogenesis (Devine and Kittler, 2018; Misgeld and T. L. Schwarz, 2017), yet mitochondria motility decreases gradually as neurons mature (Lewis et al., 2016; Moutaux et al., 2018; Obashi and Okabe, 2013). Specifically, mitochondria are recruited at immature presynaptic boutons (J. Courchet et al., 2013) where they remain captured by an actin-dependent mechanism (Gutnick et al., 2019). Here, we further demonstrate that mitochondria are recruited after, and not prior to, branch formation. Furthermore, mitochondria are not recruited to any given presynaptic boutons, but are preferentially recruited to branch-associated boutons. This differs from observations in sensory and retinal neurons where mitochondria recruitment to hot-spots of local translation induce filopodia and branch formation (Spillane et al., 2013; Wong et al., 2017). It is possible that this discrepancy stems from distinct modalities of collateral branch formation. Indeed cortical PN branches emerge from regions where the growth cone paused during axon elongation (Kalil and Dent, 2014; Szebenyi et al., 1998), whereas NGF-induced branch can form anyplace along the axon (Gallo and Letourneau, 1998). Interestingly although NUAK1 expression is largely enriched in the developing cortex and hippocampus (Hirano et al., 2006), studies suggest other AMPK-RKs can functionally operate in regulating axon branching in sensory neurons (Lilley et al., 2013), potentially explaining mechanistic differences in the modalities of branch formation in different neuron types. Of note our study does not rule out a possible role of NUAK1 and mitochondria recruitment in supporting local protein synthesis in cortical neurons.

Our results reveal that mitochondrial function is needed to support axonal branching in connection with presynaptic boutons. Mature synapses have high metabolic need. Recent studies identified that synaptic ATP comes mostly from glucose uptake and metabolism locally (Ashrafi et al., 2017) and involves the two main components of glucose, ie. glycolysis (Jang et al., 2016; Rangaraju et al., 2014) and mitochondrial oxidative phosphorylations (Ashrafi et al., 2020; Pathak et al., 2015). However, it is unlikely that ATP by itself is sufficient to support branch formation and stabilization. Indeed the metabolic functions of mitochondria are not restricted to ATP production but contribute to most metabolic pathways in the cell including the metabolism of lipids, amino acids, nucleic acids or neurotransmitters (MartínezReyes and Chandel, 2020). Furthermore, axon outgrowth and branching is dependent on local calcium dynamics (Hutchins and Kalil, 2008) and calcium buffering by mitochondria is important for cortical PN axons branching (Lewis et al., 2018). Mitochondrial ATP production and calcium dynamics are intertwined (Ashrafi et al., 2020; Llorente-Folch et al., 2013). Further studies are warranted to carefully dissect the metabolome of mitochondria captured at axonal branchpoints in developing axons.

Although our evidence clearly indicate that mitochondrial function is impaired in NUAK1 deficient neurons, the molecular link between NUAK1 and mitochondria is so far unknown. In c-Myc dependent cancer cells, a knockdown of NUAK1 downregulates the expression of several essential mitochondrial proteins including multiple components of the Electron Transport Chain (ETC) (Liu et al., 2012). This broad effect on mitochondrial proteome suggests that the kinase NUAK1 might have an indirect effect on mitochondrial composition. Interestingly NUAK1 has recently been linked to RNA biogenesis (Cossa et al., 2020). Furthermore NUAK1 
is an AMPK-related kinase (Lizcano et al., 2004), and AMPK activity is decreased upon NUAK1 knockdown in cancer cells (Liu et al., 2012). Interestingly AMPK acts on mitochondria biogenesis through the transcription factor PGC1a, and on mitochondria dynamics through the Mitochondrial Fission Factor MFF, which are both involved in axon morphogenesis (Lewis et al., 2018; Vaarmann et al., 2016). The potential role of a NUAK1/AMPK crosstalk on axonal mitochondria function and axonal branching remains to be studied. Finally, NUAK1 has a wellcharacterized action on actomyosin organization through the phosphorylation of the myosin phosphatase regulator MYPT1 (Zagórska et al., 2010). Interestingly a recent study uncovered that actomyosin contractility promotes axonal transport, and specifically that actomyosin affects the speed of mitochondrial transport in the axon (T. Wang et al., 2020). Furthermore in sensory neurons actomyosin contraction at branchpoint antagonizes the formation of microtubule bundles in NGF-induced branch formation (Ketschek et al., 2015). To which extent a NUAK1/MYPT1 complex controls mitochondria positioning and axon morphogenesis through the regulation of actomyosin should be explored.

Mitochondrial defects can cause an increased ROS production, which has been linked to defects in cortical circuits formation (Fernandez et al., 2019). The use of ROS scavenger can alleviate some of the anatomical and behavioral phenotypes in a mouse model of schizophrenia (Cabungcal et al., 2014). However, we did not observe any benefit of N-AC treatment in NUAK1-deficient neurons. On the contrary L-Carnitine rescued axonal branching in vitro and in vivo. L-Carnitine has demonstrated some beneficial effects on axonal development and branching in sensory neurons (Sainath et al., 2017). Furthermore L-Carnitine has anti-depressant effect mediated by an upregulation of metabolic activity (Cherix et al., 2020; Filiou and Sandi, 2019). Our work provides further evidence that L-Carnitine might be of therapeutic interest in correcting mitochondrial disfunction and metabolic imbalance during neurodevelopment.

\section{ACKNOWLEDGEMENTS}

The authors thank members of the Courchet lab and Institut NeuroMyoGène for useful comments and discussion. We are sincerely grateful to Franck Polleux for his support in building this project. We wish to thank Franck Polleux, Tommy Lewis, Yusuke Hirabayashi, SeokKyu Kwon, Rémi Mounier, Hélène Puccio and Thomas Boulin for technical advice, suggestions, and critical reading of the manuscript, and Agnès Duplany, Anne Devin and Arnaud Mourier for suggestions and technical help in setting up biochemical assays. We thank the personnel from the SCAR and ALECS-SPF mouse facility for animal care. This work was supported by the Fondation pour la Recherche Medicale (AJE20141031276) and ERC Starting Grant (678302-NEUROMET). M.L. was the recipient of a grant from AFM-telethon.

M.L. and J.C. conceived the experiments and interpreted the results. M.L., R.D.R., C.B., L.J. and A.A. performed the experiments. J.C. and G.M-D. performed and interpreted IUCE experiments. M.L. and A.G. performed neuronal cultures. J.C. prepared the manuscript.

\section{MATERIALS AND METHODS Animals}

Mice breeding and handling was performed by following National Institutes of Health guidelines and the French and European legislation. Experimental protocols were approved by the CECCAPP Ethics committee (C2EA15) of the University of Lyon. Timepregnant females were maintained in a $12 \mathrm{hr}$ light/dark cycle and obtained by overnight breeding with males of the same strain. Noon following breeding was considered as E0.5. Floxed NUAK1 mice (Nuak $1^{\text {tm1a(KOMP)Wtsi }) ~ h a v e ~ b e e n ~ d e s c r i b e d ~}$ previously (V. Courchet et al., 2018). The NexCRE mouse line (Neurod6 ${ }^{\text {tm1(cre)Kan }}$ (Goebbels et al., 2006) were provided by Sandrine Humbert (Grenoble Institute of Neuroscience, France). Animals were maintained on a C57BI/6J background.

\section{DNA and plasmids}

Endotoxin-free plasmid DNA was obtained using Macherey Nagel midi-prep kit. We used the following, previously described plasmids: empty vector pCAGIRES-GFP (pCIG2), CRE- expressing vector pCAGCRE-IRES-GFP (pCIG2-CRE) (Hand et al., 2005), mVENUS expressing vector pSCV2 (Hand and Polleux, 2011), pLKO, pCIG2-shSNPH, pCAGmitoDsRed (J. Courchet et al., 2013), pFUGWPercevalHR (Tantama et al., 2013), pCAGmTagBFP2 and pCAG-mito-mTagBFP2 (Lewis et al., 2016).

pCAG-mito-KillerRed was created by cloning the photosensitizer KillerRed targeted to the mitochondria with two mitochondria targeting sequences (MTS, derived from subunit 8 of human cytochrome $\mathrm{C}$ oxidase) into a pCAG vector between Xhol and Notl sites, following PCR amplification from a pCMV-mito-KillerRed plasmid (Evrogen). mScarleti cDNA was amplified by PCR from a pmScarlet-i_C1 plasmid (gift from Dorus Gadella, Addgene \#85044) (Bindels et al., 2017) and cloned into a pCAG2 
backbone between Xhol and EcoRI sites. pCAGmito-Grx1-roGFP2 and pCAG-cyto-Grx1-roGFP2 (Gutscher et al., 2008), pCAG-CRE, and pCAGvGlut1-GFP (Herzog et al., 2011) were a kind gift from Tommy L Lewis (OMRF, USA), Seok-Kyu Kwon (KIST, Korea) and Etienne Herzog (U Bordeaux, France), respectively.

\section{Primary neuronal culture}

The electroporation of dorsal telencephalic progenitors was performed by injecting plasmid DNA (1-2 $\mu \mathrm{g} / \mu \mathrm{L}$ of endotoxin-free plasmid DNA) plus $0.5 \%$ Fast Green (Sigma; 1:20 ratio) using a Picospritzer III microinjector (Harvard Apparatus) into the lateral ventricles of isolated E15.5 embryonic mouse heads (Polleux and Ghosh, 2002). Electroporation were performed with gold-coated electrodes (GenePads 5 $\mathrm{mm}, \mathrm{BTX}$ ) using an ECM 830 electroporator (BTX) and the following parameters: five pulses of $100 \mathrm{msec}$, $150 \mathrm{msec}$ interval, at $20 \mathrm{~V}$. Immediately after electroporation, cortices were dissected in Hank's buffered salt solution (HBSS) supplemented with HEPES (pH 7.4; $2.5 \mathrm{mM}), \mathrm{CaCl} 2$ (1 mM, Sigma), MgSO4 (1 mM, Sigma), NaHCO3 (4 mM, Sigma), and D-glucose (30 mM, Sigma), hereafter referred to as complete HBSS (cHBSS). Isolated cortices were dissociated in cHBSS containing papain (Worthington, $20 \mathrm{U} / \mathrm{mg}$ at least) for $20 \mathrm{~min}$ at $37^{\circ} \mathrm{C}$. Cortices were washed once in cHBSS containing DNase I $(2.5 \mathrm{mg} / \mathrm{mL}$, Sigma), then 3 times in cHBSS before being manipulated by trituration. Cells were then plated at $125.10^{3}$ cells per $35 \mathrm{~mm}$ glass bottom dish (MatTek) coated with poly-D-lysine $(0.1 \mathrm{mg} / \mathrm{mL})$ and laminin $(0.01 \mathrm{mg} / \mathrm{mL})$ and cultured for $5-7$ days in Neurobasal medium supplemented with B27 (1x), N2 (1x), Glutamax $(2 \mathrm{mM})$, and penicillin $(10 \mathrm{U} / \mathrm{mL})$ streptomycin $(0.1 \mathrm{mg} / \mathrm{mL})$.

\section{In Utero Cortical Electroporation}

Timed-pregnant NUAK1 $1^{\mathrm{F} / \mathrm{F}}$ females were mated with $\mathrm{Nex}^{\mathrm{CRE} /+} ; \mathrm{NUAK} 1^{\mathrm{F} / \mathrm{F}}$ males. At E15.5, we performed in Utero Cortical Electroporation as described in (Meyer-Dilhet and J. Courchet, 2020). A mix containing $1 \mu \mathrm{g} / \mu \mathrm{l}$ endotoxin-free plasmid DNA (pCAG-mScarlet-i) plus 0.5\% Fast Green (Sigma; 1:20 ratio) was injected into one lateral hemisphere. Electroporation was performed using an ECM 830 electroporator (BTX) using four pulses of $45 \mathrm{~V}$ with $500 \mathrm{mSec}$ interval to target cortical progenitors. Animals were sacrificed at Postnatal day 21 by terminal perfusion of $4 \%$ paraformaldehyde (PFA, Electron Microscopy Sciences) followed by $2 \mathrm{~h}$ postfixation in 4\% PFA. In the treated group, L-Carnitine (Isulik 20, Sogeval laboratories) was provided in the drinking water from detection of pregnancy (E13.5) to P21.

\section{Drug treatments}

Unless indicated otherwise, drugs were from SigmaAldrich and diluted in water (see Supplementary Resource Table). For experiments of mitochondria inactivation (Figure 1), cells were treated with low doses or Rotenone $(10,25$ or $50 \mathrm{nM})$. For in vitro rescue experiments (Figure 6), neurons were treated at 2 DIV with either L-Carnitine $(1 \mathrm{mM})$, Vitamin K2 (Menaquinone K4) $(1 \mu \mathrm{M}$ in ethanol), N-Acetyl-LCystein (1mM).

For measurements of mitochondrial Inner Membrane potential, neurons were pre-incubated in cHBSS during $30 \mathrm{~min}$ at $37^{\circ} \mathrm{C}$, then incubated in cHBSS containing $20 \mathrm{nM}$ of TMRE during $30 \mathrm{~min}$ at $37^{\circ} \mathrm{C}$. Medium was replaced by cHBSS containing $5 \mathrm{nM}$ of TMRE immediately before live-imaging.

\section{Immunostaining histochemistry}

Cells were fixed for $15 \mathrm{~min}$ at room temperature in $4 \%$ $(\mathrm{w} / \mathrm{v})$ paraformaldehyde in PBS, washed 3 times in PBS, then permeabilized for $1 \mathrm{hr}$ in Permeabilization buffer (PB: 0.3\% Triton X-100, 0.3\% BSA (Sigma), in PBS). Primary antibodies were incubated for $2 \mathrm{hr}$ at room temperature in $\mathrm{PB}$. Secondary antibodies were incubated for $1 \mathrm{hr}$ at room temperature. Coverslips (BioCoat) were mounted on slides with Fluoromount $G$ (EMS). Primary antibodies used for immunohistochemistry and immunocytochemistry in this study are chicken anti-GFP (Rockland) (1:2000) and anti-CRE (Millipore) (1:1000). All secondary antibodies were Alexa-conjugated (Invitrogen) and used at a 1:1000 dilution. Nuclear DNA was stained using Hoechst 33258 (1:10,000, Pierce).

\section{Immunohistochemistry}

At P21, mice were sacrificed by intracardiac perfusion of PFA (4\% in PBS) followed by a 2 hours postfixation of the whole brain in a $4 \%$ PFA solution. $75 \mu \mathrm{m}$ thick sections were performed using a Leica VT1000S vibratome. Slices were permeabilized for 30 minutes in PB, then incubated overnight with primary antibodies (chicken anti-GFP, Rockland) diluted at 1:2000 in PB. The following day, we performed 3 washes in PBS $1 X$, then incubated slices in secondary antibody-containing PB (Goat antichicken antibody, Alexa 488, 1:2000, life technology). Nuclear DNA was stained using Hoechst 33258 (1:5000).

\section{Western blotting}

Neurons were lysed in ice-cold Lysis Buffer (LB) containing 50mM Tris (ph8) (Euromedex), 0,5\% sodium deoxycholate (Sigma), 0,1\% SDS (Sigma), $600 \mathrm{mMNaCl}$ (Sigma) and 1X protease and 1X phosphatase mixture inhibitors (Roche). Neurons put in Bioruptor (Diagenode) for break nucleus and DNA 
(8 cycles with $15 \mathrm{sec}$ in Time on and $60 \mathrm{sec}$ in time off). $25 \mu \mathrm{g}$ aliquots of lysate were separated by electrophoresis on a $12 \%$ and $15 \%$ SDSpolyacrylamide gel and transferred on a polyvinylidene difluoride (PVDF) membrane (Amersham). Incubation with primary antibody was performed overnight in TBS, 0,1\% Tween, 5\% BSA and anti-OXPHOS antibody (abcam 110413) to $1 / 1000$ dilution or anti-Actin antibody (MP Biomedicals) to $1 / 5000$ dilution or anti-TOM20(Cell Signaling) to $1 / 1000$ dilution. The next day, membranes were incubated at room temperature for $1 \mathrm{hr}$ with HRP-linked secondary antibodies in TBS, $0,1 \%$ Tween. Western-blot revelation was performed using ECL Prime (Merk, Sigma). Imaging and analysis were performed on a chemidoc imager (Biorad) using the ImageQuant software. Images presented in the figures have been cropped around the expected bands for figure design purpose.

\section{Metabolomic flux analyzes}

We used a Seahorse XFe24 analyzer (Agilent) with the Glycolysis and Mito Stress test kits. Neurons were plated at 100,000 cells per well in Seahorse compatible 24 well plates and metabolic activity was measured at 7 days in vitro. The assay was conducted in Modified HBSS (1XHBSS supplemented with glucose $(3.5 \mathrm{~g} / \mathrm{L})$, Sodium pyruvate $1 \mathrm{mM}$, Glutamax $1 \mathrm{X}, \mathrm{CaCl} 21 \mathrm{mM}, \mathrm{MgSO} 4$ $1 \mathrm{mM}, \mathrm{pH} 7.4$ ). Following measurement, neurons were lysed in ice-cold lysis buffer (LB) and protein concentration was measured by Bradford for posthoc normalization.

\section{Mitochondria DNA}

Mitochondrial DNA was measured by qPCR following a protocol described elsewhere (Oruganty-Das et al., 2012). 7DIV primary neurons DNA was extracted by whole cell lysis in lysis buffer (Tris pH8 100mM, EDTA $5 \mathrm{mM}$, SDS $0.2 \%, \mathrm{NaCl} 200 \mathrm{mM}$, proteinase $\mathrm{K}$ $0.5 \mathrm{mg} / \mathrm{mL}$ ) followed by isopropanol precipitation. Quantitative PCR was performed with the CFXconnect thermal cycler (BioRad). The following primers were used: mtDNA_F: ACCATTTGCAGACGCCATAA, mtDNA_R: TGAAATTGTTTGGGCTACGG, betatub_F: GCCAGAGTGGTGCAGGAAA, betatub_R: TCACCACGTCCAGGACAG.

\section{Biochemical Assay}

Biochemical assays were performed on mouse cortex samples from NUAK1 KO, NUAK1 HET or NUAK1 WT mice. Samples were subjected to a chemical lysis using RIPA buffer $(150 \mathrm{mM} \mathrm{NaCl}, 0,5 \mathrm{M}$ EDTA ph8, $50 \mathrm{mM}$ Tris $\mathrm{pH} \quad 8 ; 1 \%$ NP- $40,0.5 \%$ sodium deoxycolate, $0.1 \%$ SDS) and followed by a mechanical lysis using the Precellys Evolution.

Enzymatic activity (EA) was determined by measuring absorbance using a PowerWave XS plate reader (BioTek). We used the Beer Lambert law EA= Mean $V(\varepsilon \times I)$ where $I$ is the width of the tank $(I=0.4$ $\mathrm{cm}$ ) and Mean $\mathrm{V}$ was expressed in $\mathrm{mDO} / \mathrm{min}$. For Succinate deshydrogenase activity assay, $\varepsilon=21000$ $\mathrm{uA} / \mathrm{M} / \mathrm{cm}$. For Citrate synthase activity assay, $\varepsilon=$ $13600 \mathrm{uA} / \mathrm{M} / \mathrm{cm}$.

SDH activity was measured from a volume of $10 \mu \mathrm{L}$ $(50 \mu \mathrm{g}$ of total proteins) diluted in $95 \mu \mathrm{L}$ of specific reaction buffer $\left(65 \mu \mathrm{L}\right.$ of $50 \mathrm{mM} \mathrm{KH}_{2} \mathrm{PO}_{4}, \mathrm{pH} 7.2,15 \mu \mathrm{L}$ of $70 \mathrm{mM}$ Succinate, $15 \mu \mathrm{L}$ of $560 \mu \mathrm{M}$ DCIP). Absorbance at $412 \mathrm{~nm}$ was performed over 15 minutes at $37^{\circ} \mathrm{C}$ (one read per 10 seconds).

CS activity was measured from a volume of $20 \mu \mathrm{L}$ $(100 \mu \mathrm{g}$ of total proteins) diluted in $90 \mu \mathrm{L}$ of specific reaction buffer $\left(65 \mu \mathrm{L}\right.$ of $50 \mathrm{mM} \mathrm{KH}_{2} \mathrm{PO}_{4}, \mathrm{pH} 7.5,10 \mu \mathrm{L}$ of Acetyl-CoA $4.4 \mathrm{mM}, 10 \mu \mathrm{L}$ of Oxaloacetate $4.4 \mathrm{mM}$, $10 \mu \mathrm{L}$ of $150 \mathrm{mM}$ DTNB). Absorbance at $600 \mathrm{~nm}$ was performed over 15 minutes at room temperature (one read per 10 seconds).

\section{Image Acquisition and Analyses}

Confocal images were acquired in $1024 \times 1024$ mode with a Nikon Ti-E microscope equipped with the C2 laser scanning confocal microscope. Time-lapse images were acquired in $1024 \times 1024$ mode using a CMOS ORCA-Flash 4.0 Camera (Hamamatsu). Microscope control and image analysis was performed using the Nikon software NIS-Elements (Nikon). We used the following objective lenses (Nikon): 10x PlanApo; NA 0.45, 20x PlanApo VC; NA $0.75,60 x$ Apo; NA 1.4. When live-cell imaging was carried out, the temperature was maintained at $37^{\circ} \mathrm{C}$ and $\mathrm{CO} 2$ at $5 \% \mathrm{v} / \mathrm{v}$ in a humidified atmosphere. Livecell imaging was performed in cHBSS. Representative neurons were isolated from the rest of the image using ImageJ. Contrast was enhanced and background (autofluorescence of no transfected neurons in culture) removed for better illustration of axons morphology. Kymographs were created with NIS-Elements.

\section{Quantifications and statistical analyses}

Statistical analyses were performed using Prism (GraphPad). Statistical tests and number of replicates are indicated in figures legend. For axonal morphogenesis experiments, we performed large field acquisition of neuronal cultures (typically a $4 \times 4$ tiling scan using a $20 x$ objective). All neurons on the reconstituted image were quantified and axon length was measured with the Nikon NIS Elements software. Axons shorter than $80 \mu \mathrm{m}$ were not counted. Quantifications were performed blind to genotype. 
bioRxiv preprint doi: https://doi.org/10.1101/2020.05.18.102582; this version posted May 20, 2020. The copyright holder for this preprint (which was not certified by peer review) is the author/funder, who has granted bioRxiv a license to display the preprint in perpetuity. It is made available under aCC-BY-NC-ND 4.0 International license.

\section{REFERENCES}

Alemany, S., Ribasés, M., Vilor Tejedor, N., Bustamante, M., Sánchez Mora, C., Bosch, R., Richarte, V., Cormand, B., Casas, M., Ramos Quiroga, J.A., Sunyer, J., 2015. New suggestive genetic loci and biological pathways for attention function in adult attention-deficit/hyperactivity disorder. Am. J. Med. Genet. B Neuropsychiatr. Genet. doi:10.1002/ajmg.b.32341

Ashrafi, G., de Juan-Sanz, J., Farrell, R.J., Ryan, T.A., 2020. Molecular Tuning of the Axonal Mitochondrial $\mathrm{Ca} 2+$ Uniporter Ensures Metabolic Flexibility of Neurotransmission. Neuron 105, 678-687.e5. doi:10.1016/j.neuron.2019.11.020

Ashrafi, G., Wu, Z., Farrell, R.J., Ryan, T.A., 2017. GLUT4 Mobilization Supports Energetic Demands of Active Synapses. Neuron 93, 606-615.e3. doi:10.1016/j.neuron.2016.12.020

Attwell, D., Laughlin, S.B., 2001. An energy budget for signaling in the grey matter of the brain. J. Cereb. Blood Flow Metab. 21, 1133-1145. doi:10.1097/00004647-200110000-00001

Bindels, D.S., Haarbosch, L., van Weeren, L., Postma, M., Wiese, K.E., Mastop, M., Aumonier, S., Gotthard, G., Royant, A., Hink, M.A., Gadella, T.W.J., Jr, 2017. mScarlet: a bright monomeric red fluorescent protein for cellular imaging. Nat. Methods 14, 53-56. doi:10.1038/nmeth.4074

Brosig, A., Fuchs, J., Ipek, F., Kroon, C., Schrötter, S., Vadhvani, M., Polyzou, A., Ledderose, J., van Diepen, M., Holzhütter, H.-G., Trimbuch, T., Gimber, N., Schmoranzer, J., Lieberam, I., Rosenmund, C., Spahn, C., Scheerer, P., Szczepek, M., Leondaritis, G., Eickholt, B.J., 2019. The Axonal Membrane Protein PRG2 Inhibits PTEN and Directs Growth to Branches. Cell Rep 29, 2028-2040.e8. doi:10.1016/j.celrep.2019.10.039

Bulina, M.E., Chudakov, D.M., Britanova, O.V., Yanushevich, Y.G., Staroverov, D.B., Chepurnykh, T.V., Merzlyak, E.M., Shkrob, M.A., Lukyanov, S., Lukyanov, K.A., 2006a. A genetically encoded photosensitizer. Nat. Biotechnol. 24, 95-99. doi:10.1038/nbt1175

Bulina, M.E., Lukyanov, K.A., Britanova, O.V., Onichtchouk, D., Lukyanov, S., Chudakov, D.M., 2006b. Chromophore-assisted light inactivation (CALI) using the phototoxic fluorescent protein KillerRed. Nat Protoc 1, 947-953. doi:10.1038/nprot.2006.89

Cabungcal, J.-H., Counotte, D.S., Lewis, E., Tejeda, H.A., Piantadosi, P., Pollock, C., Calhoon, G.G., Sullivan, E., Presgraves, E., Kil, J., Hong, L.E., Cuenod, M., Do, K.Q., O'Donnell, P., 2014. Juvenile antioxidant treatment prevents adult deficits in a developmental model of schizophrenia. Neuron 83, 1073-1084. doi:10.1016/j.neuron.2014.07.028

Cherix, A., Larrieu, T., Grosse, J., Rodrigues, J., McEwen, B., Nasca, C., Gruetter, R., Sandi, C., 2020. Metabolic signature in nucleus accumbens for antidepressant-like effects of acetyl-L-carnitine. Elife 9. doi:10.7554/eLife.50631

Chiechio, S., Canonico, P.L., Grilli, M., 2017. IAcetylcarnitine: A Mechanistically Distinctive and Potentially Rapid-Acting Antidepressant Drug. Int J Mol Sci 19. doi:10.3390/ijms19010011

Cioni, J.-M., Lin, J.Q., Holtermann, A.V., Koppers, M., Jakobs, M.A.H., Azizi, A., Turner-Bridger, B., Shigeoka, T., Franze, K., Harris, W.A., Holt, C.E.,
2019. Late Endosomes Act as mRNA Translation Platforms and Sustain Mitochondria in Axons. Cell 176, 56-72.e15. doi:10.1016/j.cell.2018.11.030

Cossa, G., Roeschert, I., Prinz, F., Baluapuri, A., Silveira Vidal, R., Schülein-Völk, C., Chang, Y.-C., Ade, C.P., Mastrobuoni, G., Girard, C., Wortmann, L., Walz, S., Lührmann, R., Kempa, S., Kuster, B., Wolf, E., Mumberg, D., Eilers, M., 2020. Localized Inhibition of Protein Phosphatase 1 by NUAK1 Promotes Spliceosome Activity and Reveals a MYC-Sensitive Feedback Control of Transcription. Molecular Cell. doi:10.1016/j.molcel.2020.01.008

Courchet, J., Lewis, T.L., Lee, S., Courchet, V., Liou, D.Y., Aizawa, S., Polleux, F., 2013. Terminal axon branching is regulated by the LKB1-NUAK1 kinase pathway via presynaptic mitochondrial capture. Cell 153, 1510-1525. doi:10.1016/j.cell.2013.05.021

Courchet, V., Roberts, A.J., Meyer-Dilhet, G., Del Carmine, P., Lewis, T.L., Polleux, F., Courchet, J., 2018. Haploinsufficiency of autism spectrum disorder candidate gene NUAK1 impairs cortical development and behavior in mice. Nat Commun 9, 4289. doi:10.1038/s41467-018-06584-5

del Pino, I., Rico, B., Marín, O., 2018. Neural circuit dysfunction in mouse models of neurodevelopmental disorders. Current Opinion in Neurobiology 48, 174182. doi:10.1016/j.conb.2017.12.013

Dent, E.W., Callaway, J.L., Szebenyi, G., Baas, P.W., Kalil, K., 1999. Reorganization and movement of microtubules in axonal growth cones and developing interstitial branches. J. Neurosci. 19, 8894-8908. doi:10.1523/JNEUROSCI.19-20-08894.1999

Dent, E.W., Kalil, K., 2001. Axon branching requires interactions between dynamic microtubules and actin filaments. J. Neurosci. 21, 9757-9769. doi:10.1523/JNEUROSCI.21-24-09757.2001

Devine, M.J., Kittler, J.T., 2018. Mitochondria at the neuronal presynapse in health and disease. Nature Reviews Neuroscience 19, 63-80. doi:10.1038/nrn.2017.170

Dickey, A.S., Strack, S., 2011. PKA/AKAP1 and $P P 2 A / B \beta 2$ regulate neuronal morphogenesis via Drp1 phosphorylation and mitochondrial bioenergetics. J. Neurosci. 31, 15716-15726. doi:10.1523/JNEUROSCI.3159-11.2011

Fernandez, A., Meechan, D.W., Karpinski, B.A., Paronett, E.M., Bryan, C.A., Rutz, H.L., Radin, E.A., Lubin, N., Bonner, E.R., Popratiloff, A., Rothblat, L.A., Maynard, T.M., LaMantia, A.-S., 2019. Mitochondrial Dysfunction Leads to Cortical Under-Connectivity and Cognitive Impairment. Neuron 102, 11271142.e3. doi:10.1016/j.neuron.2019.04.013

Filiou, M.D., Sandi, C., 2019. Anxiety and Brain Mitochondria: A Bidirectional Crosstalk. Trends Neurosci. 42, 573-588. doi:10.1016/j.tins.2019.07.002

Gallo, G., Letourneau, P.C., 1998. Localized sources of neurotrophins initiate axon collateral sprouting. Journal of Neuroscience 18, 5403-5414. doi:10.1523/JNEUROSCI.18-14-05403.1998

Goebbels, S., Bormuth, I., Bode, U., Hermanson, O., Schwab, M.H., Nave, K.-A., 2006. Genetic targeting of principal neurons in neocortex and hippocampus of NEX-Cre mice. Genesis 44, 611-621. doi:10.1002/dvg.20256

Gutnick, A., Banghart, M.R., West, E.R., Schwarz, T.L., 2019. The light-sensitive dimerizer zapalog reveals distinct modes of immobilization for axonal mitochondria. Nat. Cell Biol. 96, 1. doi:10.1038/s41556-019-0317-2 
bioRxiv preprint doi: https://doi.org/10.1101/2020.05.18.102582; this version posted May 20, 2020. The copyright holder for this preprint (which was not certified by peer review) is the author/funder, who has granted bioRxiv a license to display the preprint in perpetuity. It is made available under aCC-BY-NC-ND 4.0 International license.

Gutscher, M., Pauleau, A.-L., Marty, L., Brach, T., Wabnitz, G.H., Samstag, Y., Meyer, A.J., Dick, T.P., 2008. Real-time imaging of the intracellular glutathione redox potential. Nat. Methods 5, 553559. doi:10.1038/nmeth.1212

Hand, R., Bortone, D., Mattar, P., Nguyen, L., Heng, J.I.T., Guerrier, S., Boutt, E., Peters, E., Barnes, A.P., Parras, C., Schuurmans, C., Guillemot, F., Polleux, F., 2005. Phosphorylation of Neurogenin2 specifies the migration properties and the dendritic morphology of pyramidal neurons in the neocortex. Neuron 48, 45-62. doi:10.1016/j.neuron.2005.08.032

Hand, R., Polleux, F., 2011. Neurogenin2 regulates the initial axon guidance of cortical pyramidal neurons projecting medially to the corpus callosum. Neural Dev 6, 30. doi:10.1186/1749-8104-6-30

Harris, J.J., Jolivet, R., Attwell, D., 2012. Synaptic energy use and supply. Neuron 75, 762-777. doi:10.1016/j.neuron.2012.08.019

Herzog, E., Nadrigny, F., Silm, K., Biesemann, C., Helling, I., Bersot, T., Steffens, H., Schwartzmann, R., Nägerl, U.V., Mestikawy, El, S., Rhee, J., Kirchhoff, F., Brose, N., 2011. In vivo imaging of intersynaptic vesicle exchange using VGLUT1 Venus knock-in mice. J. Neurosci. 31, 15544-15559. doi:10.1523/JNEUROSCI.2073-11.2011

Hirabayashi, Y., Kwon, S.-K., Paek, H., Pernice, W.M., Paul, M.A., Lee, J., Erfani, P., Raczkowski, A., Petrey, D.S., Pon, L.A., Polleux, F., 2017. ERmitochondria tethering by PDZD8 regulates $\mathrm{Ca}(2+)$ dynamics in mammalian neurons. Science 358, 623630. doi:10.1126/science.aan6009

Hirano, M., Kiyonari, H., Inoue, A., Furushima, K., Murata, T., Suda, Y., Aizawa, S., 2006. A new serine/threonine protein kinase, Omphk1, essential to ventral body wall formation. Dev Dyn 235, 22292237. doi: $10.1002 / d v d y .20823$

Hollenbeck, P.J., Saxton, W.M., 2005. The axonal transport of mitochondria. J. Cell. Sci. 118, 54115419. doi:10.1242/jcs.02745

Hu, J., Bai, X., Bowen, J.R., Dolat, L., Korobova, F., Yu, W., Baas, P.W., Svitkina, T., Gallo, G., Spiliotis, E.T., 2012. Septin-driven coordination of actin and microtubule remodeling regulates the collateral branching of axons. Curr. Biol. 22, 1109-1115. doi:10.1016/j.cub.2012.04.019

Hutchins, B.I., Kalil, K., 2008. Differential outgrowth of axons and their branches is regulated by localized calcium transients. J. Neurosci. 28, 143-153. doi:10.1523/JNEUROSCI.4548-07.2008

lossifov, I., O'Roak, B.J., Sanders, S.J., Ronemus, M., Krumm, N., Levy, D., Stessman, H.A., Witherspoon, K.T., Vives, L., Patterson, K.E., Smith, J.D., Paeper, B., Nickerson, D.A., Dea, J., Dong, S., Gonzalez, L.E., Mandell, J.D., Mane, S.M., Murtha, M.T., Sullivan, C.A., Walker, M.F., Waqar, Z., Wei, L., Willsey, A.J., Yamrom, B., Lee, Y.-H., Grabowska, E., Dalkic, E., Wang, Z., Marks, S., Andrews, P., Leotta, A., Kendall, J., Hakker, I., Rosenbaum, J., Ma, B., Rodgers, L., Troge, J., Narzisi, G., Yoon, S., Schatz, M.C., Ye, K., McCombie, W.R., Shendure, J., Eichler, E.E., State, M.W., Wigler, M., 2014. The contribution of de novo coding mutations to autism spectrum disorder. Nature 515, 216-221. doi:10.1038/nature13908

lossifov, I., Ronemus, M., Levy, D., Wang, Z., Hakker, I., Rosenbaum, J., Yamrom, B., Lee, Y.-H., Narzisi, G., Leotta, A., Kendall, J., Grabowska, E., Ma, B., Marks, S., Rodgers, L., Stepansky, A., Troge, J., Andrews, P., Bekritsky, M., Pradhan, K., Ghiban, E., Kramer,
M., Parla, J., Demeter, R., Fulton, L.L., Fulton, R.S., Magrini, V.J., Ye, K., Darnell, J.C., Darnell, R.B., Mardis, E.R., Wilson, R.K., Schatz, M.C., McCombie, W.R., Wigler, M., 2012. De novo gene disruptions in children on the autistic spectrum. Neuron 74, 285299. doi:10.1016/j.neuron.2012.04.009

Jang, S., Nelson, J.C., Bend, E.G., Rodríguez-Laureano, L., Tueros, F.G., Cartagenova, L., Underwood, K., Jorgensen, E.M., Colón-Ramos, D.A., 2016. Glycolytic Enzymes Localize to Synapses under Energy Stress to Support Synaptic Function. Neuron 90, 278-291. doi:10.1016/j.neuron.2016.03.011

Javaherian, A., Cline, H.T., 2005. Coordinated motor neuron axon growth and neuromuscular synaptogenesis are promoted by CPG15 in vivo. Neuron 45, 505-512. doi:10.1016/j.neuron.2004.12.051

Johnson, M.R., Shkura, K., Langley, S.R., DelahayeDuriez, A., Srivastava, P., Hill, W.D., Rackham, O.J.L., Davies, G., Harris, S.E., Moreno-Moral, A., Rotival, M., Speed, D., Petrovski, S., Katz, A., Hayward, C., Porteous, D.J., Smith, B.H., Padmanabhan, S., Hocking, L.J., Starr, J.M., Liewald, D.C., Visconti, A., Falchi, M., Bottolo, L., Rossetti, T., Danis, B., Mazzuferi, M., Foerch, P., Grote, A., Helmstaedter, C., Becker, A.J., Kaminski, R.M., Deary, I.J., Petretto, E., 2016. Systems genetics identifies a convergent gene network for cognition and neurodevelopmental disease. Nat Neurosci 19, 223-232. doi:10.1038/nn.4205

Kalil, K., Dent, E.W., 2014. Branch management: mechanisms of axon branching in the developing vertebrate CNS. Nature Reviews Neuroscience 15 7-18. doi:10.1038/nrn3650

Ketschek, A., Jones, S., Spillane, M., Korobova, F., Svitkina, T., Gallo, G., 2015. Nerve growth factor promotes reorganization of the axonal microtubule array at sites of axon collateral branching. Dev Neurobiol 75, 1441-1461. doi:10.1002/dneu.22294

Klein Gunnewiek, T.M., Van Hugte, E.J.H., Frega, M., Guardia, G.S., Foreman, K., Panneman, D., Mossink, B., Linda, K., Keller, J.M., Schubert, D., Cassiman, D., Rodenburg, R., Vidal Folch, N., Oglesbee, D., Perales-Clemente, E., Nelson, T.J., Morava, E., Nadif Kasri, N., Kozicz, T., 2020. m.3243A > G-Induced Mitochondrial Dysfunction Impairs Human Neuronal Development and Reduces Neuronal Network Activity and Synchronicity. Cell Rep 31, 107538. doi:10.1016/j.celrep.2020.107538

Kwon, S.-K., Sando, R., Lewis, T.L., Hirabayashi, Y., Maximov, A., Polleux, F., 2016. LKB1 Regulates Mitochondria-Dependent Presynaptic Calcium Clearance and Neurotransmitter Release Properties at Excitatory Synapses along Cortical Axons. PLoS Biol. 14, e1002516. doi:10.1371/journal.pbio.1002516

Lasagna-Reeves, C.A., de Haro, M., Hao, S., Park, J., Rousseaux, M.W.C., Al-Ramahi, I., Jafar-Nejad, P., Vilanova-Velez, L., See, L., De Maio, A., Nitschke, L., Wu, Z., Troncoso, J.C., Westbrook, T.F., Tang, J., Botas, J., Zoghbi, H.Y., 2016. Reduction of Nuak1 Decreases Tau and Reverses Phenotypes in a Tauopathy Mouse Model. Neuron 92, 407-418. doi:10.1016/j.neuron.2016.09.022

Lee, A., Hirabayashi, Y., Kwon, S.-K., Lewis, T.L., Polleux, F., 2018. Emerging roles of mitochondria in synaptic transmission and neurodegeneration. Curr Opin Physiol 3, 82-93. doi:10.1016/j.cophys.2018.03.009

Lewis, T.L., Courchet, J., Polleux, F., 2013. Cell biology in neuroscience: Cellular and molecular mechanisms 
bioRxiv preprint doi: https://doi.org/10.1101/2020.05.18.102582; this version posted May 20, 2020. The copyright holder for this preprint (which was not certified by peer review) is the author/funder, who has granted bioRxiv a license to display the preprint in perpetuity. It is made available under aCC-BY-NC-ND 4.0 International license.

underlying axon formation, growth, and branching. J. Cell Biol. 202, 837-848. doi:10.1083/jcb.201305098

Lewis, T.L., Kwon, S.-K., Lee, A., Shaw, R., Polleux, F., 2018. MFF-dependent mitochondrial fission regulates presynaptic release and axon branching by limiting axonal mitochondria size. Nat Commun 9, 5008. doi:10.1038/s41467-018-07416-2

Lewis, T.L., Turi, G.F., Kwon, S.-K., Losonczy, A., Polleux, F., 2016. Progressive Decrease of Mitochondrial Motility during Maturation of Cortical Axons In Vitro and In Vivo. Curr. Biol. 26, 2602-2608. doi:10.1016/j.cub.2016.07.064

Lilley, B.N., Pan, Y.A., Sanes, J.R., 2013. SAD kinases sculpt axonal arbors of sensory neurons through long- and short-term responses to neurotrophin signals. Neuron 79, 39-53. doi:10.1016/j.neuron.2013.05.017

Liu, L., Ulbrich, J., Müller, J., Wüstefeld, T., Aeberhard, L., Kress, T.R., Muthalagu, N., Rycak, L., Rudalska, R., Moll, R., Kempa, S., Zender, L., Eilers, M., Murphy, D.J., 2012. Deregulated MYC expression induces dependence upon AMPK-related kinase 5. Nature 483, 608-612. doi:10.1038/nature10927

Lizcano, J.M., Göransson, O., Toth, R., Deak, M., Morrice, N.A., Boudeau, J., Hawley, S.A., Udd, L., Mäkelä, T.P., Hardie, D.G., Alessi, D.R., 2004. LKB1 is a master kinase that activates 13 kinases of the AMPK subfamily, including MARK/PAR-1. EMBO J. 23, 833-843. doi:10.1038/sj.emboj.7600110

Llorente-Folch, I., Rueda, C.B., Amigo, I., del Arco, A., Saheki, T., Pardo, B., Satrústegui, J., 2013. Calciumregulation of mitochondrial respiration maintains ATP homeostasis and requires ARALAR/AGC1-malate aspartate shuttle in intact cortical neurons. Journal of Neuroscience 33, 13957-71-13971a. doi:10.1523/JNEUROSCI.0929-13.2013

Martínez-Reyes, I., Chandel, N.S., 2020. Mitochondrial TCA cycle metabolites control physiology and disease. Nat Commun 11, 102. doi:10.1038/s41467019-13668-3

Meyer, M.P., Smith, S.J., 2006. Evidence from in vivo imaging that synaptogenesis guides the growth and branching of axonal arbors by two distinct mechanisms. J. Neurosci. 26, 3604-3614. doi:10.1523/JNEUROSCI.0223-06.2006

Meyer-Dilhet, G., Courchet, J., 2020. In Utero Cortical Electroporation of Plasmids in the Mouse Embryo: STAR Protocols. STAR Protocols 1. doi:10.1016/j.xpro.2020.100027

Misgeld, T., Schwarz, T.L., 2017. Mitostasis in Neurons: Maintaining Mitochondria in an Extended Cellular Architecture. Neuron 96, 651-666. doi:10.1016/j.neuron.2017.09.055

Mizuno, H., Hirano, T., Tagawa, Y., 2007. Evidence for activity-dependent cortical wiring: formation of interhemispheric connections in neonatal mouse visual cortex requires projection neuron activity. J. Neurosci. 27, 6760-6770. doi:10.1523/JNEUROSCI.1215-07.2007

Moutaux, E., Christaller, W., Scaramuzzino, C., Genoux, A., Charlot, B., Cazorla, M., Saudou, F., 2018. Neuronal network maturation differently affects secretory vesicles and mitochondria transport in axons. Scientific Reports 8, 13429. doi:10.1038/s41598-018-31759-x

Obashi, K., Okabe, S., 2013. Regulation of mitochondrial dynamics and distribution by synapse position and neuronal activity in the axon. Eur $\mathrm{J}$ Neurosci 38, 2350-2363. doi:10.1111/ejn.12263
Ohmura, T., Shioi, G., Hirano, M., Aizawa, S., 2012. Neural tube defects by NUAK1 and NUAK2 double mutation. Dev Dyn 241, 1350-1364. doi:10.1002/dvdy.23816

Oruganty-Das, A., Ng, T., Udagawa, T., Goh, E.L.K., Richter, J.D., 2012. Translational control of mitochondrial energy production mediates neuron morphogenesis. Cell Metabolism 16, 789-800. doi:10.1016/j.cmet.2012.11.002

Pathak, D., Shields, L.Y., Mendelsohn, B.A., Haddad, D., Lin, W., Gerencser, A.A., Kim, H., Brand, M.D., Edwards, R., Nakamura, K., 2015. The role of mitochondrially derived ATP in synaptic vesicle recycling. J. Biol. Chem. 290, 22325-22336. doi:10.1074/jbc.M115.656405

Piven, J., Elison, J.T., Zylka, M.J., 2017. Toward a conceptual framework for early brain and behavior development in autism. Mol. Psychiatry 22, 13851394. doi:10.1038/mp.2017.131

Polleux, F., Ghosh, A., 2002. The slice overlay assay: a versatile tool to study the influence of extracellular signals on neuronal development. Sci. STKE 2002 , pl9-pl9. doi:10.1126/stke.2002.136.pl9

Ponomareva, O.Y., Holmen, I.C., Sperry, A.J., Eliceiri, K.W., Halloran, M.C., 2014. Calsyntenin-1 regulates axon branching and endosomal trafficking during sensory neuron development in vivo. J. Neurosci. 34 9235-9248. doi:10.1523/JNEUROSCI.0561-14.2014

Rangaraju, V., Calloway, N., Ryan, T.A., 2014. Activitydriven local ATP synthesis is required for synaptic function. Cell 156, 825-835. doi:10.1016/j.cell.2013.12.042

Rangaraju, V., Lewis, T.L., Hirabayashi, Y., Bergami, M., Motori, E., Cartoni, R., Kwon, S.-K., Courchet, J. 2019. Pleiotropic Mitochondria: The Influence of Mitochondria on Neuronal Development and Disease. J. Neurosci. 39, 8200-8208. doi:10.1523/JNEUROSCI.1157-19.2019

Rossi, M.J., Pekkurnaz, G., 2019. Powerhouse of the mind: mitochondrial plasticity at the synapse. Current Opinion in Neurobiology 57, 149-155. doi:10.1016/j.conb.2019.02.001

Ruthazer, E.S., Li, J., Cline, H.T., 2006. Stabilization of axon branch dynamics by synaptic maturation. J. Neurosci. 26, 3594-3603. doi:10.1523/JNEUROSCI.0069-06.2006

Sainath, R., Ketschek, A., Grandi, L., Gallo, G., 2017. CSPGs inhibit axon branching by impairing mitochondria-dependent regulation of actin dynamics and axonal translation. Dev Neurobiol 77, 454-473. doi:10.1002/dneu.22420

Schwarz, A., Rapaport, E., Hirschberg, K., Futerman, A.H., 1995. A regulatory role for sphingolipids in neuronal growth. Inhibition of sphingolipid synthesis and degradation have opposite effects on axonal branching. J. Biol. Chem. 270, 10990-10998. doi:10.1074/jbc.270.18.10990

Spillane, M., Ketschek, A., Donnelly, C.J., Pacheco, A., Twiss, J.L., Gallo, G., 2012. Nerve growth factorinduced formation of axonal filopodia and collateral branches involves the intra-axonal synthesis of regulators of the actin-nucleating Arp2/3 complex. J. Neurosci. 32, 17671-17689. doi:10.1523/JNEUROSCI.1079-12.2012

Spillane, M., Ketschek, A., Merianda, T.T., Twiss, J.L., Gallo, G., 2013. Mitochondria coordinate sites of axon branching through localized intra-axonal protein synthesis. Cell Rep 5, 1564-1575. doi:10.1016/j.celrep.2013.11.022 
bioRxiv preprint doi: https://doi.org/10.1101/2020.05.18.102582; this version posted May 20, 2020. The copyright holder for this preprint (which was not certified by peer review) is the author/funder, who has granted bioRxiv a license to display the preprint in perpetuity. It is made available under aCC-BY-NC-ND 4.0 International license.

Szebenyi, G., Callaway, J.L., Dent, E.W., Kalil, K., 1998. Interstitial branches develop from active regions of the axon demarcated by the primary growth cone during pausing behaviors. Journal of Neuroscience 18, 7930-7940. doi:10.1523/JNEUROSCI.18-1907930.1998

Tantama, M., Martínez-François, J.R., Mongeon, R., Yellen, G., 2013. Imaging energy status in live cells with a fluorescent biosensor of the intracellular ATP. to-ADP ratio. Nat Commun 4, 2550. doi:10.1038/ncomms3550

Tefera, T.W., Borges, K., 2016. Metabolic Dysfunctions in Amyotrophic Lateral Sclerosis Pathogenesis and Potential Metabolic Treatments. Front. Neurosci. 10, 611. doi:10.3389/fnins.2016.00611

Vaarmann, A., Mandel, M., Zeb, A., Wareski, P., Liiv, J., Kuum, M., Antsov, E., Liiv, M., Cagalinec, M., Choubey, V., Kaasik, A., 2016. Mitochondrial biogenesis is required for axonal growth. Development 143, 1981-1992. doi:10.1242/dev.128926

Vaccaro, V., Devine, M.J., Higgs, N.F., Kittler, J.T., 2017. Miro1-dependent mitochondrial positioning drives the rescaling of presynaptic $\mathrm{Ca} 2+$ signals during homeostatic plasticity. EMBO Rep 18, 231-240. doi:10.15252/embr.201642710

Villegas, R., Martinez, N.W., Lillo, J., Pihan, P., Hernandez, D., Twiss, J.L., Court, F.A., 2014. Calcium Release from Intra-Axonal Endoplasmic Reticulum Leads to Axon Degeneration through Mitochondrial Dysfunction. Journal of Neuroscience 34, 7179-7189. doi:10.1523/JNEUROSCI.478413.2014

Vojinovic, D., Adams, H.H., Jian, X., Yang, Q., Smith, A.V., Bis, J.C., Teumer, A., Scholz, M., Armstrong, N.J., Hofer, E., Saba, Y., Luciano, M., Bernard, M., Trompet, S., Yang, J., Gillespie, N.A., van der Lee, S.J., Neumann, A., Ahmad, S., Andreassen, O.A., Ames, D., Amin, N., Arfanakis, K., Bastin, M.E., Becker, D.M., Beiser, A.S., Beyer, F., Brodaty, H., Bryan, R.N., Bülow, R., Dale, A.M., De Jager, P.L., Deary, I.J., DeCarli, C., Fleischman, D.A., Gottesman, R.F., van der Grond, J., Gudnason, V., Harris, T.B., Homuth, G., Knopman, D.S., Kwok, J.B. Lewis, C.E., Li, S., Loeffler, M., Lopez, O.L., Maillard, P., Marroun, El, H., Mather, K.A., Mosley, T.H., Muetzel, R.L., Nauck, M., Nyquist, P.A., Panizzon, M.S., Pausova, Z., Psaty, B.M., Rice, K., Rotter, J.I., Royle, N., Satizabal, C.L., Schmidt, R., Schofield, P.R., Schreiner, P.J., Sidney, S., Stott, D.J., Thalamuthu, A., Uitterlinden, A.G., Valdés Hernández, M.C., Vernooij, M.W., Wen, W., White, T., Witte, A.V., Wittfeld, K., Wright, M.J., Yanek, L.R., Tiemeier, H., Kremen, W.S., Bennett, D.A., Jukema, J.W., Paus, T., Wardlaw, J.M., Schmidt, H., Sachdev, P.S., Villringer, A., Grabe, H.J., Longstreth, W.T., van Duijn, C.M., Launer, L.J., Seshadri, S., Ikram, M.A., Fornage, M., 2018. Genome-wide association study of 23,500 individuals identifies 7 loci associated with brain ventricular volume. Nat Commun 9, 3945. doi:10.1038/s41467-018-06234-w

Vos, M., Esposito, G., Edirisinghe, J.N., Vilain, S., Haddad, D.M., Slabbaert, J.R., Van Meensel, S., Schaap, O., De Strooper, B., Meganathan, R., Morais, V.A., Verstreken, P., 2012. Vitamin K2 is a mitochondrial electron carrier that rescues pink1 deficiency. Science 336, 1306-1310. doi:10.1126/science.1218632

Vos, M., Lauwers, E., Verstreken, P., 2010. Synaptic mitochondria in synaptic transmission and organization of vesicle pools in health and disease. Front. Synaptic Neurosci. 2, 139. doi:10.3389/fnsyn.2010.00139

Wang, C.-L., Zhang, L., Zhou, Y., Zhou, J., Yang, X.-J., Duan, S.-M., Xiong, Z.-Q., Ding, Y.-Q., 2007. Activitydependent development of callosal projections in the somatosensory cortex. J. Neurosci. 27, 1133411342. doi:10.1523/JNEUROSCI.3380-07.2007

Wang, T., Li, W., Martin, S., Papadopulos, A., Joensuu, M., Liu, C., Jiang, A., Shamsollahi, G., Amor, R., Lanoue, V., Padmanabhan, P., Meunier, F.A., 2020. Radial contractility of actomyosin rings facilitates axonal trafficking and structural stability. J. Cell Biol. 219. doi:10.1083/jcb.201902001

Wong, H.H.-W., Lin, J.Q., Ströhl, F., Roque, C.G., Cioni, J.-M., Cagnetta, R., Turner-Bridger, B., Laine, R.F., Harris, W.A., Kaminski, C.F., Holt, C.E., 2017. RNA Docking and Local Translation Regulate Site-Specific Axon Remodeling In Vivo. Neuron 95, 852-868.e8. doi:10.1016/j.neuron.2017.07.016

Zagórska, A., Deak, M., Campbell, D.G., Banerjee, S., Hirano, M., Aizawa, S., Prescott, A.R., Alessi, D.R., 2010. New roles for the LKB1-NUAK pathway in controlling myosin phosphatase complexes and cell adhesion. Sci Signal 3, ra25-ra25. doi:10.1126/scisignal.2000616

Zanelli, S.A., Solenski, N.J., Rosenthal, R.E., Fiskum, G., 2005. Mechanisms of ischemic neuroprotection by acetyl-L-carnitine. Ann. N. Y. Acad. Sci. 1053, 153161. doi:10.1196/annals. 1344.013 